\title{
iTRAQ-based comparative proteome analyses of different growth stages revealing the regulatory role of reactive oxygen species in the fruiting body development of Ophiocordyceps sinensis
}

\author{
Xinxin Tong Equal first author, 1 , Fang Wang Equal first author, 1 , Han Zhang ${ }^{1}$, Jing Bai $^{1}$, Qiang Dong ${ }^{1}$, Pan Yue ${ }^{1}$, Xinyi Jiang ${ }^{1}$, \\ Xinrui Li ${ }^{1}{ }^{1}$ Li Wang ${ }^{1}$, Jinlin Guo ${ }^{\text {Corresp. } 1}$ \\ ${ }^{1}$ Key Laboratory of Standardization of Chinese Medicine, Ministry of Education; Key Laboratory of Systematic Research, Development and Utilization of \\ Chinese Medicine Resources in Sichuan Province-Key Laboratory Breeding Base founded by Sichuan Province, Chengdu University of Traditional Chinese \\ Medicine, Chengdu, Sichuan, China \\ Corresponding Author: Jinlin Guo \\ Email address: guo596@cdutcm.edu.cn
}

In this study, using an isobaric tags for relative and absolute quantitation (iTRAQ ) approach coupled with LC-MS / MS and bioinformatics, the proteomes were analyzed for the crucial three stages covering the fruiting body development of Ophiocordyceps sinensis, including sclerotium (ST), primordium (PR) and mature fruiting body (MF), with a focus on fruiting body development-related proteins and the potential mechanisms of the development. A total of 1875 proteins were identified. Principal Component Analysis (PCA) demonstrated that the protein patterns between PR and MF were more similar than ST. Differentially accumulated proteins (DAPs) analysis showed that there were 510, 173 and 514 DAPs in the comparisons of ST vs. PR, PR vs. MF and ST vs. MF, respectively. A total of 62 shared DAPs were identified and primarily enriched in proteins related to 'carbon transport and mechanism', 'the response to oxidative stress', 'antioxidative activity' and 'translation'. KEGG and GO databases showed that the DAPs were enriched in terms of 'primary metabolisms (amino acid /fatty acid /energy metabolism)', 'the response to oxidative stress' and 'peroxidase'. Furthermore, 34 DAPs involved in reactive oxygen species (ROS) metabolism were identified and clustered across the three stages using hierarchical clustering implemented in hCluster R package. It was suggested that their roles and the underlying mechanisms may be stage-specific. ROS may play a role in fungal pathogenicity in ST, the fruit-body initiation in PR, sexual reproduction and highland adaptation in MF. Crucial ROS-related proteins were identified, such as superoxide dismutase (SOD, T5A6F1), Nor-1(T5AFX3), electron transport protein (T5AHD1), histidine phosphotransferase (HPt, T5A9Z5) and Glutathione peroxidase (T5A9V1). Besides, the accumulation of ROS at the three stages were assayed using 2,7 - dichlorofuorescin diacetate (DCFH-DA) stanning. A much stronger ROS accumulation was detected at the 
stage MF, compared to the stages of PR and ST. Sections of ST and fruit-body part of MF were stained by DCFH-DA and observed under the fluorescencemicroscope, showing ROS was distributed within the conidiospore and ascus. Besides, SOD activity increased across the three stages, while CAT activity has a strong increasement in MF compared to the stages of ST and PR. It was suggested that ROS may act in gradient-dependent manner to regulate the fruiting body development. The coding region sequences of six DAPs were analyzed at mRNA level by quantitative real-time PCR (qRT-PCR). The results supports the result of DAPs analysis and the proteome sequencing data. Our findings offer the perspective of proteome to understand the biology of fruiting body development and highland adaptation in $O$. sinensis, which would inform the big industry of this valuable fungus. 
1 iTRAQ-based Comparative Proteome Analyses of Different Growth Stages

2 Revealing the Regulatory Role of Reactive Oxygen Species in the Fruiting Body

\section{Development of Ophiocordyceps sinensis}

4

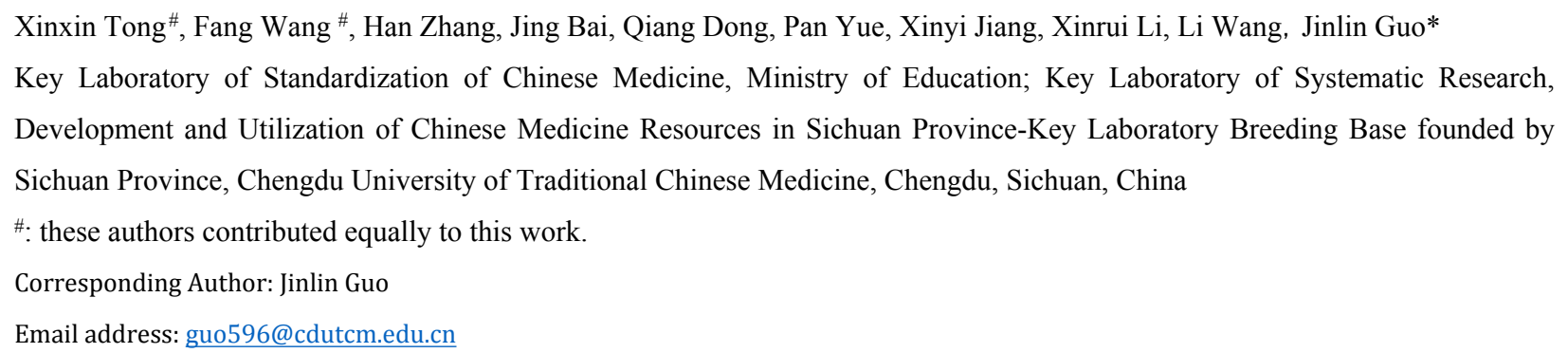

\section{Abstract}

In this study, using an isobaric tags for relative and absolute quantitation (iTRAQ) approach coupled with LC-MS / MS and bioinformatics, the proteomes were analyzed for the crucial three stages covering the fruiting body development of Ophiocordyceps sinensis, including sclerotium (ST), primordium (PR) and mature fruiting body (MF), with a focus on fruiting body development-related proteins and the potential mechanisms of the development. A total of 1875 proteins were identified. Principal Component Analysis (PCA) demonstrated that the protein patterns between PR and MF were more similar than ST. Differentially accumulated proteins (DAPs) analysis showed that there were 510, 173 and 514 DAPs in the comparisons of ST vs. PR, PR vs. MF and ST vs. MF, respectively. A total of 62 shared DAPs were identified and primarily enriched in proteins related to "carbon transport and mechanism', 'the response to oxidative stress', 'antioxidative activity' and 'translation'. KEGG and GO databases showed that the DAPs were enriched in terms of 'primary metabolisms (amino acid /fatty acid /energy metabolism)', 'the response to oxidative stress' and 'peroxidase'. Furthermore, 34 DAPs involved in reactive oxygen species (ROS) metabolism were identified and clustered across the three stages using hierarchical clustering implemented in hCluster R package. It was suggested that their roles and the underlying mechanisms may be stage-specific. ROS may play a role in fungal pathogenicity in ST, the fruit-body initiation in PR, sexual reproduction and highland adaptation in MF. Crucial ROS-related proteins were identified, such as superoxide dismutase (SOD, T5A6F1), Nor-1(T5AFX3), electron transport protein (T5AHD1), histidine phosphotransferase (HPt, T5A9Z5) and Glutathione peroxidase (T5A9V1). Besides, the accumulation of ROS at the three stages were assayed using 2,7 - dichlorofuorescin diacetate (DCFH-DA) stanning. A much stronger ROS accumulation was detected at the stage MF, compared to the stages of PR and ST. Sections of ST and fruitbody part of MF were stained by DCFH-DA and observed under the fluorescence microscope, showing ROS was distributed within the conidiospore and ascus. Besides, SOD activity increased across the three stages, while CAT activity has a strong increasement in MF compared to the stages of ST and PR. It was suggested that ROS may act in gradient-dependent manner to regulate the fruiting body development. The coding region sequences of six DAPs were analyzed at mRNA level by quantitative real-time PCR (qRT-PCR). The results supports the result of DAPs analysis and the proteome sequencing data. Our findings offer the perspective of proteome to 
understand the biology of fruiting body development and highland adaptation in $O$. sinensis, which would inform the big industry of this valuable fungus.

Keywords: Ophiocordyceps sinensis; comparative proteome analyses; fruiting body development; reactive oxygen species.

\section{Introduction}

Ophiocordyceps sinensis (Berk.), syn. Cordyceps sinensis, belongs to Ascomycetes and has been used as medicinal treatments and healthy food in some Asia countries over 2000 years [1]. It is commonly named as "Dong Chong Xia Chao", specifically parasitizing the larva of ghost moth caterpillars (Thitarodes spp.) and making a complex of the fungal stroma and the remains of the caterpillar [1,2]. Over 20 bioactive ingredients have been reported, such as adenosine, cordyceps acid, ergosterol and polysaccharides, exerting multiple pharmacological effects, including anti-inflammatory, anti-tumor, immunomodulating and antioxidative activities, etc. [3]. Recent years, overexploitation, habitat excavation and the upward of snow line aggravated the yield decreases of $O$. sinensis, resulting in extremely high price, approximately US $\$ 60,000$ per $\mathrm{kg}$ for high quality products [4]. The success of large-scale cultivation has only recently been achieved [4-6]. An understanding of the biology of the fruiting body development would enhance scientific research, impact the big industry and protect this precious resources for sustainable usage.

$O$. sinensis infects the host larva. Then the larva progressively becomes stiff and coated with mycelia on the remaining exoskeleton of the insects [4], and a small stroma bud emerges from the head of the sclerotium and form the stalked fruiting body [4]. During the infection, insect hosts often rapidly produce plenty of ROS to directly kill pathogens [5], as a response, pathogen fungi develop an adequate ROS antioxidant defense system [5]. Previous study showed that oxidoreductase putatively involved in the ecdysteroid metabolism of insect molting may have potential relationship with the fungal pathogenicity in O. sinensis [7]. Besides, the sclerotial differentiation state in Sclerotium rolfsii concurred with increasing levels of lipid peroxides [8]. In Morchella importuna, the MAPK signaling pathway was activated and passed the signal from an area of high oxidative stress to a low area to initiate sclerotial formation along with the increasing levels of SOD [9]. Recently, the morphologic studies showed that the numbers of hyphal bodies and the conversion of hyphal bodies into hyphae may play important roles in the mummification of the injected larvae [10,11].

O. sinensis naturally inhabits the alpine environments of the Qinghai-Tibetan Plateau with an average altitude of over $4,000 \mathrm{~m} \mathrm{[12].} \mathrm{The} \mathrm{ecological} \mathrm{conditions} \mathrm{have} \mathrm{been} \mathrm{demonstrated} \mathrm{to} \mathrm{initiate} \mathrm{and} \mathrm{promote} \mathrm{the}$ formation of the fruiting body [13]. Both orientation and position of the neck on perithecium were lightdependent in Neurospora. crassa [14], and the number of protoperithecia greatly increases under blue-light illumination [15-17]. Light controls the balance of asexual versus sexual reproduction of Aspergillus nidulans [17].Omics studies promoted to understand the biology of the fungus guided by the ecological stimuli [4]. Genome analysis of the highland adaption showed that the signals of positive selection for genes encoding for peroxidases in $O$. sinensis compared to other plain-dwelling fungi, probably contributing to the detoxification of strong ROS induced by high intensity UV [7]. NADPH oxidase-generated ROS regulates sexual development in A. nidulans [17]. The change in the distribution of ROS caused by the sod-1 mutation was found to be an important factor to cause loss of the light-induced perithecial polarity $[18,19]$, suggesting that intracellular ROS may function as a novel light signal transducer in the perithecial polarity. Besides, the 12 shared DEGs 
80

81

(differentially expressed genes) detected among all five comparisons of adjacent growth stages of $O$. sinensis were primarily enriched in the terms of 'the response to oxidative stress' and 'peroxidase activity' [20]. Of the 18 candidates associated with the fruiting body development, most were involved in terms of 'oxidative stress' and / or 'osmotic response' in A. nidulans [21]. Our previous study showed that some genes involved in ROS system, such as SOD, NADPH oxidase (NOX) and cytochrome oxidase, might play important roles in lightdependent morphogenesis on the perithecia, ascus or perithecia formation [22]. Based on above evidences, ROS may serve as an active regulator of the fruiting body formation and differentiation in $O$. sinensis guided by environmental stresses.

In this study, O. sinensis samples of three major developmental stages were harvested from the artificial cultivation workshop and comparative proteomic analyses was conducted using iTRAQ technology [23]. In particular, we focused on the differential expression of fruiting body development related proteins and the expression profiles of ROS-related proteins in $O$. sinensis. This study provides an important insight into the crucial development-related proteins and the potential regulatory mechanism of ROS metabolism system in fungal pathogenicity and fruiting body development, which would further benefit the large-scale cultivation and the sustainable development of this precious bio-resource.

\section{Methods}

\section{Collection of $\boldsymbol{O}$. sinensis samples in three major growth stages}

Three major developmental stages of $O$. sinensis were harvested from the artificial cultivation workshop at our lab in Chengdu University of Traditional Chinese Medicine (TCM) (Fig. 1). The mummified larvae coated with mycelia before stroma development were designated as the sclerotium (ST). The samples of stroma with lengths $<1 \mathrm{~cm}$ were designated as the primordium (PR), and the fruiting body with mature ascus and ascospores was designated as the mature fruiting body (MF).

\section{Protein preparation}

Samples $(0.1 \mathrm{~g})$ were ground into powder in liquid nitrogen, lysed in a solution with 100:1 (w/v) urea lysis buffer containing 8M Urea, $2 \mathrm{mM}$ EDTA, $10 \mathrm{mM}$ iodoacetamide (DTT), $25 \mathrm{mM}$ iodoacetamide (IAA), 1\% protease inhibitor cocktail (Minipore), and sonicated for $1 \min (2 \mathrm{~s}, 4 \mathrm{~s})$. The proteins in the pooled supernatant was precipitated by addition of 3 times volume of acetone and incubated at $-20{ }^{\circ} \mathrm{C}$ for $2 \mathrm{~h}$. Following centrifugation at $12000 \mathrm{rpm}$ for $15 \mathrm{~min}$ at $4{ }^{\circ} \mathrm{C}$, the pellet was collected and then air dried. Protein was extracted by resuspending the dry pellet in UT buffer ( $8 \mathrm{M}$ Urea, $100 \mathrm{mM}$ Triethyl ammonium Bicarbonate, TEAB). Protein concentration was determined with a Modified Bradford Protein Assay Kit (Bio-Rad, Hercules, CA, USA) according to the manufacturer's instructions, and then samples were kept in $-80{ }^{\circ} \mathrm{C}$ prior to use.

\section{Peptide Isobaric Labeling}

For each sample, $100 \mu \mathrm{g}$ protein was used for digestion. The protein solution was reduced with $10 \mathrm{mM}$ DTT for $1 \mathrm{~h}$ at $37^{\circ} \mathrm{C}$ and alkylated with $55 \mathrm{mM}$ iodoacetamide (IAM) for $30 \mathrm{~min}$ at room temperature in darkness. For trypsin digestion, the protein sample was diluted by adding $100 \mathrm{mM}$ TEAB to obtain urea concentrations less than $2 \mathrm{M}$. Then the protein suspensions were digested with Sequencing Grade Modified Trypsin (Promega, Madison, WI, USA, $1 / 50$ protein mass for the first digestion at $37^{\circ} \mathrm{C}$ overnight, and then with trypsin $(1 / 100$ protein mass) for a second digestion for $4 \mathrm{~h}$.

Following trypsin digestion, protein samples were desalted using Strata X SPE column (Phenomenex Inc; 
121 Torrance, CA, USA) and vacuum-dried using a SpeedVac concentrator (Thermo, San Jose, CA). Peptide was reconstituted in $20 \mu \mathrm{L} 500 \mathrm{mM}$ TEAB and processed according to the manufacturer's protocol for 8 - plex iTRAQ kit (Sigma, Aldrich, USA). Briefly, one unit of iTRAQ reagent was all added to peptide solution after thawed and dissolved in $50 \mu \mathrm{L}$ isopropanol. The peptide samples were incubated with $100 \mu \mathrm{g}$ for $2 \mathrm{~h}$ at room temperature and pooled, desalted and dried by vacuum centrifugation.

\section{HPLC Fractionation and High-resolution LC-MS/MS analysis based on Q Exactive}

The dried and labeled peptide was reconstituted with HPLC solution A ( $\%$ acetonitrile, ACN), pH 10, and then fractionated by high pH reverse-phase HPLC using Waters Bridge Peptide BEH C18 (130 А, $3.5 \mu$ m, 4.6 $\times 250 \mathrm{~mm}$ ). The peptides were eluted with a liner gradient of $2-98 \% \mathrm{ACN}$ in $\mathrm{pH} 10$ at a speed of $0.5 \mathrm{ml} / \mathrm{min}$ over $88 \mathrm{~min}$ into 60 fractions, and then the peptides were condensed into 20 fractions and dried by vacuum centrifugation. The peptide fractions were desalted using Ziptip C18 following the manufacturer's instructions, and finally dried under vacuum. The samples were stored at $-20^{\circ} \mathrm{C}$ till $\mathrm{MS}$ analysis was performed.

The iTRAQ-labeled samples were reconstituted in $0.1 \%$ formamide (FA), directly loaded into an Acclaim PepMap ${ }^{\circledR} 100$ C18 reversed-phase pre-column $(3 \mu \mathrm{m}, 100 \AA, 75 \mu \mathrm{m} \times 2 \mathrm{~cm}$, Thermo Fisher Scientific, San Joes, USA ) at $5 \mu \mathrm{L} / \mathrm{min}$ in $100 \%$ solvent A (0.1 M acetic acid in water), and analyzed by NanoLC 1000 LC - MS / MS using a Proxeon EASY-nLC 1000 coupled to Thermo Fisher Q Exactive (Thermo Fisher Scientific, San Joes, USA). Peptide sequential separation using a reversed-phase pre-column a (Acclaim PepMap ${ }^{\circledR}$ RSLC 139 C18, $2 \mu \mathrm{m}, 100 \AA, 50 \mu \mathrm{m} \times 15 \mathrm{~cm}$ ) was conducted using a gradient of an increase from 0 $\%$ to $8 \%$ solvent $\mathrm{B}(0.1 \% \mathrm{FA}$ in $98 \% \mathrm{ACN})$ over $5 \mathrm{~min}, 8 \%$ to $25 \%$ solvent B over $35 \mathrm{~min}, 25 \%$ to $98 \%$ solvent B during 10 minutes, $5 \mu \mathrm{L} / \mathrm{min}$ in $100 \%$ solvent $\mathrm{A}(0.1 \mathrm{M}$ acetic acid in water) and kept in $98 \%$ in 8 min at a constant flow rate of $300 \mathrm{nl} /$ min on an EASY-nLC 1000 system. The eluent was sprayed with an NSI source at an electrospray voltage of $2.5 \mathrm{kV}$. The mass spectrometer was operated in data-dependent mode to switch automatically between MS and MS / MS. Full-scan MS spectra (from m/z 350 to 1800) were acquired in the Orbitrap with a resolution of 70, 000. Ion fragments were detected in the Orbitrap at a resolution of 17,500 . MS data were obtained by selecting the 15-most-abundant precursors ions present in the survey scan (300-1,800 $\mathrm{m} / \mathrm{z}$ ) for decision-tree-based ion trap higher-energy collisional dissociation (HCD) fragmentation. The collision energy was set at $32 \%$ for HCD. Dynamic exclusion duration was $10.0 \mathrm{~s}$.

\section{Data processing}

The MS/MS raw data were analyzed by using the Sequest software integration in Proteome Discoverer (version 1.3, Thermo Scientific) and searched against Ophiocordyceps sinensis database (http://www.plantkingdomgdb.com/ophiocordyceps_sinensis/data/pep/Ophiocordyceps_sinensis_Protein. fas). The parameters were as follows: trypsin chosen as the cleavage enzyme, two missed cleavages, carbamidomethyl set as a fixed modification; and oxidation (M), NTerm Acetylation, as well as iTRAQ labeling were designated as variable modifications. The searches were performed using a peptide mass tolerance of $20 \mathrm{ppm}$ and a product ion tolerance of $0.05 \mathrm{Da}$, resulting in $5 \%$ false discovery rate (FDR).

For visualization, PCA was performed. For the determination of DAPs, fold change was calculated as the average values of four biological repeats. Subsequently, proteins with a change ratio $>1.2$ and $p$-value $<0.05$, were considered to be significantly changed.

To determine the functional property of the proteins, their sequences were mapped to Gene Ontology (GO) annotation using UniProt-GOA database (www. http://www.ebi.ac.uk/GOA/) [24 ]. Kyoto Encyclopedia of 
162 Genes and Genomes (KEGG) database ((http://www.genome.jp/kegg/) and the COG (Cluster of Orthologous 163 Groups) database (http://www.ncbi.nlm.nih.gov/COG/) were used to classify and group the proteins [25]. Firstly, 164 KEGG online service tools KAAS was used to annotate protein's KEGG database description. Then mapping 165 the annotation result on the KEGG pathway database using KEGG online service tools KEGG mapper 166 (http://geneontology.org/). For each category, a two-tailed Fisher's exact test was employed to test the out using standard false discovery rate control methods and with a corrected $p$-value $<0.05$ is considered significant. The expression patterns of DAPs involved in ROS - related GO annotation with $p-$ value $<0.05$ across the growth stages were further clustered by one - way hierarchical clustering implemented in hCluster R package (Euclidean distance, average linkage clustering). Cluster membership were visualized by a heat map using the "heatmap" function from the $\mathrm{R}$-package.

\section{Reactive oxygen species (ROS) measurement}

To detect ROS level in the samples derived from the three stages, DCFH-DA (Nanjing Jiancheng Bioengineering Institute, Nanjing, China) for reactive species staining was performed according to the manufacturer's instructions. In brief, $0.5 \mathrm{~g}$ tissue was added with $2 \mathrm{ml}$ Phosphate Buffered Saline (PBS) buffer containing $137 \mathrm{mM} \mathrm{NaCl}, 2.7 \mathrm{mM} \mathrm{KCl}, 1.5 \mathrm{mM} \mathrm{KH}_{2} \mathrm{PO}$, $8 \mathrm{mM} \mathrm{Na}_{2} \mathrm{HPO}_{4}$ and fully homogenized. Cell suspension was collected and centrifuged at $500 \times \mathrm{g}$ for $10 \mathrm{~min}$. Then cell pellets were collected and washed twice with cooled PBS and resuspended in $1 \mathrm{ml}$ PBS at a density of at least $1 \times 10^{6}$ cells per EP tube. Cell suspension was incubated with $2 \mu 110 \mathrm{mM}$ DCFH-DA for $30 \mathrm{~min}$ at $37^{\circ} \mathrm{C}$. Finally, the fluorescence intensity was detected by using a Flex station 3 (Molecular Devices, Sunnyvale, CA, United States). The fluorescence was excited at $488 \mathrm{~nm}$, detected at $525 \mathrm{~nm}$.

Intracellular production of ROS was detected by DCFH-DA (Nanjing Jiancheng Bioengineering Institute, Nanjing, China) according to the manufacture's instruction. Slices of tissues from the samples of ST and fruiting body part of MF were treated with $5 \mu \mathrm{M}$ DCFH-DA in a $50 \mathrm{mM}$ sodium phosphate buffer (pH 7.4, PBS) and incubated for $20 \mathrm{~min}$ at $37^{\circ} \mathrm{C}$. This non polar compound is actively taken up by cells and converted by esterases in DCFH, a non-fluorescent molecule, which is rapidly oxidized to the highly fluorescent DCF by intracellular peroxides. The samples were observed under a Leica DM6B fluorescence inverted microscopy at $488 \mathrm{~nm}$ excitation and photographed.

\section{SOD and CAT activities assay}

SOD activity was evaluated by using SOD activity assay kit (Nanjing Jiancheng Bioengineering Institute, Nanjing, China) according to manufacture' s instruction, based on the auto-oxidation of hydroxylamine, with the developed blue color then measured at $560 \mathrm{~nm}$. Results are expressed as units of SOD / $\mathrm{mg}$ protein and calculated based on the formula: SOD activity $(U / \mathrm{mg})=\left(\mathrm{A}_{\text {light }}-\mathrm{A}_{\text {measure }}\right) / 50 \% \times \mathrm{A}_{\text {light }} \times \mathrm{V}_{\text {tissue }} \times$ tissue mass (mg).

CAT activity was detected by using CAT activity assay kit (Nanjing Jiancheng Bioengineering Institute, Nanjing, China) according to manufacture' s instruction. The decomposition of $\mathrm{H}_{2} \mathrm{O}_{2}$ by CAT was stopped by the addition of ammonium molybdate. The remaining $\mathrm{H}_{2} \mathrm{O}_{2}$ was then reacted with ammonium molybdate to generate a pale-yellow complex, which was measured at $405 \mathrm{~nm}$ [26]. The CAT activity was calculated based on the formula: CAT activity $(\mathrm{U} / \mathrm{mg})=[($ A self-control $-\mathrm{A}$ measure $) /$ Ablank $] \times 650 /$ protein concentration $(\mathrm{mg} /$ $\mathrm{ml}$ ). The protein concentration of each sample was determined using BCA protein assay kit (Thermo Fisher Scientific, Waltham, MA, USA). 


\section{qPCR validation}

Total RNA was extracted from snap-frozen samples using TRIzol reagent (Tiangen Biotech, Beijing, China), and the RNA was reverse-transcribed using the FastKing RT Kit with gDNase (Tiangen Biotech, Beijing, China). The qRT-PCR was performed by using Ultra SYBR qPCR Mixture (Cwbiotech, Co., LTD, Beijing, China) on Bio-Rad CFX 96 Real-Time PCR Detection System ( Hercules, CA, USA). Each $20 \mu \mathrm{L}$ reaction system contained $2 \mu \mathrm{L}$ cDNA $(50 \mathrm{ng} / \mu \mathrm{L}), 1 \mu \mathrm{L}$ forward primer $(10 \mu \mathrm{mol} / \mathrm{L}), 1 \mu \mathrm{L}$ reverse primer $(10 \mu \mathrm{mol} /$ L), $10 \mu \mathrm{L} 2 \times$ Ultra SYBR qPCR Mixture. Thermal cycling conditions were pre-incubation at $95{ }^{\circ} \mathrm{C}$ for $30 \mathrm{~s}$, followed by 35 cycles of denaturation at $95^{\circ} \mathrm{C}$ for $5 \mathrm{~s}$, annealing at $55^{\circ} \mathrm{C}$ for $30 \mathrm{~s}$, and an extension at $95^{\circ} \mathrm{C}$ for 15 s. 18s rRNA (GenBank Accession Number: FM164742.1) was used as the internal reference gene to normalize the gene expression data. Six DAPs were randomly selected to evaluate the consistency of the mRNA expression level. The gene-specific primers for qPCR were designed by Primer Premier 5.0 software (Premier Biosoft International, CA, USA) and listed in Table S7. The relative expression levels were calculated by using the $2^{-\Delta \Delta \mathrm{Ct}}$ method. Three biological replicates were set for each treatment.

\section{Statistical Analysis}

Proteome analyses were carried out for four independent biological repeats for each sample. Other experiments were performed using three independent biological repeats and each biological repeat was performed at least three technical repeats. All results are presented as the mean $\pm \mathrm{SD}$. Two-tailed Student's $t$ tests and graphs were performed using GraphPad Prism v 6.0c software (GraphPad Software, Inc.). A value of $P$ value $<0.05$ was considered to be statistically significant.

\section{Results and discussion}

\section{General information on iTRAQ analysis}

To explore the patterns of proteome during the development, comparative proteome analysis was performed from three growth stages of artificially cultivated $O$. sinensis (Fig.1 ). A total of 1875 proteins were identified using iTRAQ in these samples of different stages. We detected 42031, 57731, 49886 unique spectra, 18563, 25954, 20660 peptides and 17887, 25114, 19904 unique peptides in ST, PR and MF, respectively(Table 1). In this study, the most spectra results had a mass error within $\pm 5 \mathrm{ppm}$, indicating that the mass spectrometer's mass accuracy was normal (Fig.S1).The length of the peptides identified were distributed between 7 aa and 12 aa in (Fig. S2) and $90 \%$ of the peptide length was distributed within 24aa. MS data has been deposited in iProX (Integrated Proteome Resources, http://www.iprox.org/) with the primary accession code PXD021260.

\section{Proteome profile of the three stages of $O$. sinensis}

$O$. sinensis has a complex life cycle. The caterpillar infection by the fungus, primordium induction and fruiting body development remain difficult task, due to the fact that the molecular basis of its lifestyle remain cryptic [4]. To investigate the protein profiles during the growth, samples from three crucial growth stages including ST, PR and MF, were submitted for proteome analysis. Principal component analysis (PCA) revealed that the stages of PR and MF were grouped together, while the stage of ST remained separate, indicating that the differentiated stages PR and MF have much more similar protein expression profiles than the undifferentiated ST stage, similar to the result of transcriptome data (Fig. S3 ) [20, 22]. Based on a fold change $>1.2$ and a $p$ value $<0.05,1343$ significant DAPs were identified (Table S1). There are 510, 173 and 514 DAPs detected in the comparisons of ST vs. PR, PR vs. MF and ST vs. MF, respectively (Table S2 ). 62 shared DAPs were identified among the three different growth stages (Table S3) and are primarily included in terms of "carbon 
transport and mechanism', 'the response to oxidative stress', 'antioxidative activity', 'translation' and protein/amino acid synthesis. For examples, AhpC / TSA family protein (T5A9T9) and flavin-containing monooxygenase (T5AHW7) were oxidoreductases, playing roles in the response to oxidative stress. Phosphotransferase (T5AFE3) functions in carbohydrate transport, which is responsible for nutrients up-take to the cells of the developing fruiting body[27]. Eukaryotic translation initiation factors (T5ADW2, T5AAF6 ) are relevant with protein synthesis. The mutant of eukaryotic translation initiation factor EF-1 $\alpha$ resulted in the lack of ascospores or perithecia in Podospora anserine [28]. Besides, some uncharacterized proteins were also identified. Overall, the shared DAPs analyses indicated that the primary metabolisms and ROS system may play important roles in the developmental process. The roles of ROS and its underlying mechanisms needed to be further studied.

DAPs analysis showed that there are 419 up- and 91 down- regulated DAPs in the ST vs. PR comparison , 98 up- and 75 down-regulated DAPs in PR vs. MF, 441 up- and 73 down-regulated DAPs in ST vs. MF (Fig. 2, Table S2). Based on both KEGG and GO databases, we analyzed the enrichment of DAPs of the three growth stages (Fig.3, Table S4, Table S5). In ST vs. PR, DAPs were mainly enriched in GO terms of 'structure molecule activity' (GO:0005198) in cellular component, 'mitochondrial protein complex' (GO:0098798), 'nucleosome' ( GO:0000786 ) and 'DNA-protein complex'(GO:0032993) in molecular function, 'amide / peptide transport' (GO:0042886, GO:00015833), 'translation' (GO:0006412), 'cellular amide metabolic process' (GO:0043604 ) in biological process (Fig.3A, Table S4), indicating that various proteins could be synthesized during the infection. In PR vs. MF, DAPs were primarily enriched in terms of 'antioxidant activity' (GO:0016209) in MF, 'DNA packing complex' (GO:0044815), 'protein-DNA complex' (GO:0032993) and 'nucleosome' (GO:0000786) in cellular component, 'cellular oxidant detoxification' (GO:0098869), 'the response to oxidant stress / chemical stress / stress' (GO:0006979, GO:0042221, GO:0006950), 'the regulation of protein localization' (GO:0032880), 'amide/ peptide transport' (GO:0042886, GO:0015833) in biological process, indicating amino / energy and ROS metabolism might play critical roles in the fruiting body development guided by environmental stimuli (Fig.3B, Table S4). In ST vs. MF, DAPs were mainly enriched in terms of 'inner mitochondrial membrane protein complex'(GO:0098800), 'extracellular region' (GO:0005576), 'mitochondrial protein complex' (GO:0098798) in cellular component, 'peptide / amide biosynthetic process'(GO:0044455, GO:0043604), 'translation'(GO:0006412), 'generation of precursor metabolites and energy' (GO:0006091) in biological process, indicating an increased demand of energy, new proteins and metabolites in fruiting body development (Fig.3C, Table S4). In particular, ROS metabolism system would affect the development, but the underlying mechanism remains to be clarified.

To further understand biological functions of the DAPs, pathway-based analyses was performed. KEGG pathway enrichment analysis showed that aminoacyl-tRNA biosynthesis, ribosome and proteasome showed significant enrichment in the comparison of ST and PR (Fig. 4 A, Table S5), among which the pathways of 'proteasome'(map03050), 'glycan degradation'(map00511), 'aminoacyl-tRNA'(map00970) were up regulated in ST compared to PR. Aminoacyl-tRNAs are the active substrates for protein synthesis. The pathway of 'aminoacyl-tRNAs' was up-regulated in ST, indicating protein synthesis would be more active during the hostpathogen interaction[22]. The ubiquitin / 26S proteasome system was implicated in plant-pathogen interaction [28]. In $O$. sinensis, approximately $35 \%$ of proteases detected have a signal peptide, indicating a more efficient usage of secreted proteases in this fungi to adapt to the specific insect cuticles [7]. Here, some proteases were detected to be highly up-regulated in ST compared to PR (Table S6), such as serine protease (T4ZXQ6), 26S 
285

286

287

288

289

290

291

292

293

294

295

296

297

298

299

300

301

302

303

304

305

306

307

308

309

310

311

312

313

314

315

316

317

318

319

320

321

322

323

324

325

proteasome regulatory subunit (T5AL30, T5AFG8), proteasome regulatory beta unite (T5AA86, T5A8T1) and proteasome regulatory alpha unite (T5A611). Serine protease in sclerotium may be beneficial for fungus to infect its host through digesting protein component of insect cuticle[30]. Two cuticle-degrading serine proteases have been obtained in $O$. sinensis [31]. These results showed that proteases would play important roles in pathogenhost interactions in this fungus. Few related reports has been reported yet. In PR vs MF, the DAPs were enriched in pathways of 'phenylalanine, tyrosine and tryptophan biosynthesis'(map00400, map00350), 'protein processing in endoplasmic reticulum (ER)' (map04141), 'peroxisome (map04146) and fatty acid degradation' (map00071), among which the pathways of 'phenylalanine', 'tyrosine and tryptophan biosynthesis' and 'peroxisome' were up-regulated in MF compared to that in PR (Fig. 4B, Table S5), indicating that a variety of proteins may be bio-synthesized and needed for the fruit-body maturation[20, 22]. For examples, phospho-2dehydro-3-deoxyheptonate aldolase (T5ABF2) remarkably increased in MF compared to PR. This protein is the first critical step for the shikimate pathway, which is involved in the biosynthesis of aromatic amino acids like phenylalanine and tyrosine. Mutants of the corresponding genes resulted in significantly decreases of fruit-body formation and ascosporogenesis in A. nidulans [32], suggesting that shikimate pathway may participate into controlling fruit-body maturation in $O$. sinensis. Besides, the mutant of tryptophan synthase-encoding gene $\operatorname{trp} B$ or the histidine biosynthesis gene hisB leads to loss of cleistothecia production on medium with low levels of tryptophan or histidine, respectively [33-35]. Moreover, when the amounts of a single amino acid is very low, both genes would activate varieties of amino acid biosynthesis [13], indicating that amino acid / protein synthesis would be involved in the fruiting body maturation. Besides, the pathway of peroxisome was up-regulated in MF compared to PR. Peroxisomes were detected to be required for the fruiting body formation and germination of sexual spore in $P$. anserine [33]. Here, long-chain acyl-CoA synthetase \& acyl-protein synthetase (ACSLs, T5AQC4) involved in peroxisome was detected to be highly up-regulated in MF compared to PR. ACSLs is an essential enzyme for the synthesis of fatty acyl-CoA, which is mainly for synthesis of fatty acid and sterols [36]. CAR1 is necessary for peroxisome biogenesis, and the carl mutant resulted in a sterile $[37,38]$. Meanwhile, in peroxisome, mobilization of fatty acids by $\beta$-oxidation takes place, therefore, the sterile of carl mutant might be due to a disturbed fatty acid metabolism [13], suggesting that composition of fatty acids and their derivatives would be required for sexual development in $O$. sinensis. This is consistent with a high demand for energy during the fruit-body formation. On the other hand, peroxidases, SOD (T5A6F1, T5AJH5) and CAT (T5A5N4, T5AJ96), were detected up-regulated in MF compared to PR (Table S6). These enzymes convert ROS to harmless particles, protecting organism from oxidative damage by excessive ROS. Not only that, sod-1 is necessary for correct fruiting-body morphology [13], and catalase-peroxidase gene cpe was detected in cleistothecia [39], probably due to cpeA act in concert to generate the correct amount of self-induced oxidative stress during the fruiting body formation [13], suggesting that ROS gradient may play roles in the development in $O$. sinensis. In ST vs. MF, the DAPs were enriched in the pathways of 'aminoacyl-tRNAs'(map00970), 'citrate cycle (TCA)'(map00020) and 'carbon metabolism (map01200)'. These pathways were detected to be upregulated in ST compared to MF ( Fig. 4C, Table S5). Some proteins (Table S6), that are involved in the latter two metabolisms, were identified to have a higher expression levels at the stage of ST, such as succinate-CoA ligase (ADP-forming) $\alpha$ subunit (T5A666), isocitrate dehydrogenase subunit (T5A5Y2) and pyruvate dehydrogenase $\alpha$ subunit (T4ZWD4). So high amounts of energy and carbohydrates might be needed for the pathogen-host interactions and hyphae growth at the stage of ST, as well as prepared for the latter fruiting process. 
Additionally, fruiting body usually couldn't happen till severe stressors occur [40]. As far as we know, $O$. sinensis inhabits over 4,000 $\mathrm{m}$ above sea level in Qinghai-Tibetan Plateau. The fruiting-body induction and development in $O$. sinensis are tightly associated with the ecological factors specific to highland. Under certain environmental stresses, dikaryotic mycelia aggregate to form primordium, which marks the beginning of fruit body development [13]. Here, heat shock proteins Hsp 70 (T5A2W7, T5ADA9, Table S6) were detected to be up-regulated in PR compared to ST. Heat shock treatment accelerated the fruiting body formation and sporulation of Myxococcus xanthus [41], suggesting that Hsp would be induced by heat treatment and perhaps involved in the fruiting body formation. Besides, Hsp70 (T5ADA9, Table S6) has a higher expression in MF than that in ST, suggesting that this protein might be also important for fruit-body maturation. On the other hand, Hsps are also immunodominant antigens and major targets of host immune response during different types of infection [42]. Our data showed that Hsp 30 (T5AGM5) and Hsp DanJ (T5AKH0) were up-regulated in ST compared to PR (Table S6). Hsp OS (T5A0N1) and Hsp 90 (T5AEC8) have a higher expression in ST compared to MF (Table S6). These results indicated that the host larva may produce Hsps for protection when infected by the pathogenic fungus. However, the mechanism needs further studies.

\section{Signal pathway in fruiting body formation of $O$. sinensis}

Previous studies showed that mitogen-activated protein kinase (MAPK) pathway, regulate gene expression in response to extracellular stimuli that finally leads to fruiting body formation in $O$. sinensis. Our proteome data showed that the DAPs involved in MAPK signaling pathway, including G $\beta$ subunit, T5A9X0, KH domain RNA-binding protein, T5AF08, protein kinase like proteinT5A7J6 and two Ras proteins, T5AKF5, T5AA69, have a remarkably higher expression level in ST than that in the stage of MF(Table S6). In A. nidulans, rasA gene mutant cause aberrations in conidial germination and asexual development [43]. In N. crassa, as well as other filamentous ascomycetes, it was demonstrated that subunits of $\mathrm{G}$ proteins are important for hyphal growth, conidiation, and fruiting-body development [44]. Targeted disruption of two $\mathrm{G} \alpha$ subunit genes in Cryphonectria parasitica revealed roles for the gene in fungal reproduction, virulence, and vegetative growth [13]. Here, G $\beta$ subunit was detected to be up-regulated in ST compared to MF. RAS like protein subunits can regulate downstream effectors such as adenylyl cyclase (AC) and mitogen-activated protein kinase (MAPK) cascades. Besides, cAMP-dependent protein kinase regulatory subunit ( T5ANJ5) was found to be up-regulated in ST. It was suggested that G-protein signaling would be involved in the infection and hyphal growth of $O$. sinensis. On the other hand, serine/threonine-protein phosphatase (T5AGS5, Table S6) involved in MAPK signaling pathway has a significantly higher expression level in MF compared to ST. Three different MAPKs and two different MAPKKKs have been proved to be involved in fruit-body development in different mycelial ascomycetes [13]. Moreover, mutation of the corresponding genes always leads to multiple phenotypic defects in ascocarp formation. The MAPKKK NRC-1 of $N$. crassa is essential for female fertility [45]. So MAPK signaling pathway may also be involved in fruit-body development in response to extracellular stimuli in $O$. sinensis.

\section{Hierarchical clustering analysis of DAPs involved in ROS metabolism}

ROS play roles in the growth, development, defense responses against various stresses and that spatial regulation of ROS production is an important factor controlling the growth in fungi and plant. ROS production and scavenging is a dynamic oxidation-reduction process. Here, we identified the DAPs involved in ROS metabolism by looking for proteins predicted to be involved in oxidation-reduction processes. In ST vs. PR, ROS reflected in the GO annotations includes GO:0051920 ,GO:0016491, GO:0016709, GO:0016717, GO:0055114 and GO:0003824 (Fig. 3A, Table S4) In PR vs. MF, ROS reflected in GO annotations that was 
related to ROS include GO:0006979, GO:0034599, GO:0072593, GO:0042743, GO:0042744, GO:0016209, GO:0016701, GO:0016697, etc. (Fig. 3B, Table S4). In ST vs. MF, ROS reflected in GO annotations include GO:0016491, GO:0004601 and GO:0016684. (Fig. 3C, Table S4). Among them, a total of 34 DAPs involved in ROS metabolism were identified (Table S2).

Furthermore, the protein profiles of DAPs involved in ROS metabolism across the three stages were clustered (Fig. 5, Table 2). The results demonstrated that there were four proteins clusters with visible difference expression patterns (Fig. 5A-D). PR and MF stages were grouped together into one cluster indicating that PR and MF stages have more similar ROS related expression patterns than ST stage (Fig. 5E). In cluster 1, with 5 DAPs, had a gradual increase over the entire process from ST to MF, illustrating a different role for these proteins with respect to development, especially for maturation, including pyridine nucleotide-disulfide oxidoreductase (T5AE75), Superoxide dismutase (SOD, T5AJH5), electron transport protein (T5AHD1) and aldehyde dehydrogenase domain protein (T5AA56) (Table 2). For examples, in N. crassa, SOD-1 is necessary for lightdependent positioning of perithecial necks, probably due to generate a light-dependent ROS gradient that would control neck positioning [18]. SOD was successively up-regulated from PR to MF in $O$. sinensis, indicating that it may be play roles in the process of the entire fruiting body development, especially for the fruiting body maturation. As far as we know, light is required for the maturity by forming the sexual structures: sporulating structures that produce ascospore [13,15], suggesting that SOD may be light-dependent regulation of sexual development in $O$. sinensis. Besides, electron transport proteins were located within the inner membrane of mitochondria, which is responsible for energy generation. Mutants of these proteins result in lack of energy and are sterile in $N$. crassa [46]. Electron transport protein (T5AHD1) were detected to gradually increase from ST to MF, indicating an increased demand of energy during the fruiting body development, especially for sexual development. Aldehyde dehydrogenase are putative indole receptor proteins involved in multicellular development and was found to be essential for fruiting body formation in Stigmatella aurantiaca [47]. Acetaldehyde dehydrogenase of the glyoxylate pathway can be induced by heat shock in Myxococcus Xanthus [48] and was proposed to be relevant with fruiting body formation in Flammulina velutipes [49]. This protein (T5AA56) was at the highest level in MF, indicating that it might be also required for the fruiting body maturation in $O$. sinensis. probably in response to temperature-related stress.

In cluster 2, with 6 DAPs, had a sudden increase in expression upon transition from ST to PR and then a sudden decrease in expression upon shifting from PR to MF phase, indicating that they may play a major role in the fruiting body initiation, such as histidine phosphotransferase (HPt, T5A92Z), one cytochrome P450 protein (T5A735) and Mannitol-1-phosphate 5-dehydrogenase (MPD, T5AIP9) (Table 2). For examples, MPD, a main enzyme for mannitol biosynthesis, was found to be abundance in the fruiting body of $O$. sinensis, compared to that in mycelia [50]. As a result, it may increase the content of mannitol in $O$. sinensis, which was found to be related to fruiting body initiation and development of $A$. bisporus [51]. The mannitol content in the fruiting body of A. bisporus is about 8 to 20 times higher than that in mycelium [52]. Our data showed that MPD was upregulated in PR compared to the other two stages, suggested that it may be related to initiation of the fruiting body. In our study, one cytochrome P450 protein was detected to be at the highest level in PR. These enzymes are involved in secondary metabolism, oxidative and peroxidative. The mutant of eln 2 gene, encoding a novel type of cytochrome P450, resulted in the mutant phenotype of primordial shaft [53]. One explanation is that a changed catalytic activity may generate a toxic compound that affects development in the primordial shaft [53]. The relationship between cytochrome P450 and the fruiting body initiation is the focus of another project in 
our lab. Besides, HPt functions as ROS sensors and up-regulates stress-activated MAP kinase cascade, which was shown to be involved in fruiting body development in different mycelial ascomycete[54]. This protein (T5A924) was up-regulated in PR, suggesting that the initiation of the fruiting body may be depend on MAPK pathways.

Cluster 3, with 11 DAPs, was suddenly decreased from the ST to PR stage and then suddenly increased from the PR to the MF stage, including catalase (CAT, T5AL96, T5A5N4), superoxide dismutase (SOD, T5A6F1), transaldolase (T5AF35), Nor-1(T5AFX3) and glucose-methanol-choline oxidoreductase (GMCA, T5AP38), etc. (Table 2), indicating that these proteins may be play roles in the growth of ST, as well as the maturation of the fruiting body. For examples, ROS generated by microbial NADPH oxidase (NoxA) would regulate sexual development in A. nidulans [17]. NOX2, together with NOR1, controls ascospore germination in Sordaria macrospora [55]. Two NOX isoforms are required for sexual reproduction and ascospore germination in $P$. anserine [56]. Our data showed that Nor-1 was up-regulated in stages of PR and MF compared to ST, suggesting that NOX1-Nor complex system may also contribute to generate ROS, triggering spore germination in $O$. sinensis. This is the very important regulatory pathway of ROS generation and may be an integral part of fruiting-body formation in fungi. Besides, the mutant of GMCA in A. nidulans resulted in the suppression of asexual development. GMCA was also the target of FIbB, a upstream developmental activator, inducing A. nidulans asexual differentiation[57], thereby, GMCA may also play a role in the growth of hyphae and morphogenesis of sclerotia in $O$. sinensis. Besides, transaldolase is important for the balance of metabolites in the pentose-phosphate pathway (PPP), which is the major pathway for glucose metabolism, the tricarboxylic acid cycle (TCA) and carbohydrate catabolism [58]. Our data showed transaldolase is expressed at a much higher level in ST and MF than that in PR, suggesting that higher amounts of energy may be in the form of carbohydrate initially stored in the hyphae of ST and required for the fruiting body development.

In cluster 4, with 10 DAPs, has a gradual decrease across the three stages and at the highest expression level in ST, including NADPH--cytochrome P450 reductase (T5AHU7), WSC domain-containing proteins (T5ACE9), 2-nitropropane dioxygnease (2-NPD, T5AJL9), Glutathione peroxidase (T5A9V1) and peroxiredoxin (T5AAS5), etc. (Table 2). For examples, the deletion mutants of five WSC domain-containing proteins showed a delay of germination and a decrease of conidial UV-B resistance, thermotolerance or both and indicated that a significance of each WSC protein for the Beauveria bassiana adaptation to host insects [59]. This protein has a higher level in $\mathrm{ST}$ and $\mathrm{PR}$ compared to MF in $O$. sinensis, suggesting that it may contribute to $O$. sinensis adaptation to host insect or harsh physical stresses. 2-NPD, a flavin dependent enzyme, catalyzes the oxidation of nitronates to their corresponding carbonyl compounds and nitrite [60]. 2-NPD was demonstrated to be involved in vegetative growth in Pyronema confluens [61]. Our data showed that this protein was at the highest level in ST, suggesting that it may be linked with the vegetative growth or asexual development in $O$. sinensis. The $O$. sinensis genome displayed a considerable expansion of gene families that are mainly involved in fungal pathogen, peroxidase included [7]. Peroxiredoxin are regarded as one of the most prominent and integral component role in responding to di $\square$ erent levels of oxidative stress in Vibrio vulnifcus [62,63]. So these proteins may functions as signal transducers in various stress responses in $O$. sinensis. Besides, NADPH-cytochrome $\mathrm{P} 450$ reductase maybe associated to energy production and conversion for the whole developmental process in $O$. sinensis .

ROS is critical for sexual fruiting body development in filamentous fungi. In this study, the proteins involved in ROS metabolism system were proposed to play diverse roles in different growth stages in $O$. sinensis. 
They may play a role in fungal pathogenesis at the stage of ST, be related to the induction of differentiation processes in PR and trigger sexual reproduction in MF. So their exact roles and the underlying mechanism are likely to be stage-specific, which will be the focus of our another project.

\section{qRT-PCR Analysis}

To confirm the reliability of the iTRAQ sequencing data, six proteins with different direction of accumulation were selected for qRT-PCR validation, included SOD (T5A6F1), CAT( T5A5N4), NOR1(NADPH oxidases receptor-1, T5AFX3), NDK( nucleotide diphosphate kinase, T5ALL5), CYT(cytochrome, T5AKK7) and His2A(Histone 2A, T5A212). The gene - specific primers used in qRT-PCR are listed in Table S7. According to the results of qPCR, in the comparison of ST vs. PR, except for one protein ( T5A6F1) encoding gene, the expression changes of five genes detected by qPCR is similar to the direction of fold change acquired by the iTRAQ sequencing results, including four genes up- regulated, one gene down - regulated in ST compared to PR and one gene similarly expressed between the two stages (Fig. 6A). In PR vs. MF comparison, except for two proteins (T5AFX3, T5AKK7) encoding genes, the qPCR results of four genes were similar to the results of proteome analysis, including three genes up-regulated in PR, two genes down-regulated in PR and one genes similarly expressed between the two stages (Fig. 6B). So our transcription patterns of these proteins support the results of the proteomic analysis.

\section{ROS accumulation, SOD and CAT activities assay}

In order to explore the effect of ROS on the fruiting body development in $O$. sinensis, we analyzed the accumulation ROS in the crucial growth stages (ST, PR and MF), respectively. The ROS accumulation was reflected by a fluorescence intensity per $\mathrm{g}$ tissue. MF showed about ROS level significantly increased by about 1.79- and 1.58- fold in MF, compared to ST and PR, respectively (both $p<0.001$ ), while there was no significant difference between ST and PR (Fig.7), suggesting that ROS may be positively relevant to the fruiting body maturation in $O$. sinensis. In order to investigate the site of ROS production within hyphae and fruiting body, sections of the hyphae from ST and the fruiting body part from MF were stained with DCFH-DA, respectively. The result showed that ROS signals remarkably distributed within the conidiospore and ascus (Fig. 8), suggesting that ROS may promote the growth of hyphae and ascus formation. Previous study showed that Nox-generated ROS controlled sexual development in fungi [13], similar to our study.

Environmental stresses, such as intensive UV, low temperature and fungal-insect interaction, usually result in excessive ROS accumulation in O. sinensis [7]. Our proteome data showed that the DAPs were in enriched in GO term of 'cellular response to oxidative stress' in ST vs. MF. It is consistent with an increased ROS level in MF. Our data showed SOD activity remarkably increased about 3.81-fold in PR compared to ST ( $p$-value $<0.01)$, about 1.39-fold in MF compared to PR $(p$-value $<0.05)$ and about 5.3-fold in MF compared to ST ( $p$-value < 0.001) (Fig. 9A), similar to Our proteome data (Table S1). SODs catalyze dismutation of superoxide radical to produce $\mathrm{H}_{2} \mathrm{O}_{2}$ and $\mathrm{O}_{2}$ and is considered to be the first line of defense against oxidative stress in eukaryotic cells. SOD has a significant and serial increase across the three stages, indicating that it may be produced to maintain cellular redox homeostasis and prevent the cellular damage. Upon increased gene expression of $\mathrm{Cu}, \mathrm{Zn}-\mathrm{SOD}$ and $\mathrm{Mn}-\mathrm{SOD}$, the lifespan and resistance to oxidative stress also increase in the cells of S. cerevisiae [64]. On the other hand, SOD mutants of $N$. crassa were distinguished by reduction of sexual reproduction and decreased ability for formation of conidia [64]. SOD-1 involved in generating a lightdepended ROS gradient controls neck positioning in $N$. crass [13], suggesting similar mechanism in $O$. 
490 sinensis. Besides, CAT activity significantly increased by about 3.95- and 3.73-fold in MF, compared to ST and 491 PR (both $p$-value < 0.001), respectively, while there was no significant difference between ST and PR (Fig. 9B). 492 In A. nidulans, nox A is induced during sexual development, at this time, catalase-peroxidase gene is 493 transcriptionally, converting the ROS to harmless compounds, probably protecting cell from oxidative stress 494 [13]. In N. crassa, CAT-1 activity in spores was found to be 60 times higher than that in the mycelium [65]. The 495 generation and degradation of ROS level was disturbed, suggesting that ROS may act in gradient-dependent 496 manner to regulate the fruiting body development of $O$. sinensis. The underlying mechanism needs further 497 studies.

\section{Conclusion}

In this study, we used an iTRAQ quantitative approach coupled with LC-MS/MS and bioinformatics to investigate the proteomic basis of fruiting body development. Samples of three major stages (ST, PR and MF) were collected to be examined. A total of 1875 DAPs were identified. GO enrichment and KEGG analysis demonstrated that 'primary metabolisms', 'response to oxidative stress', 'antioxidative activity' were enriched during the fruiting process. Furthermore, some crucial development-related proteins were identified, such as Hsps, serine / threonine-protein phosphatase and serine proteases. The protein profiles of the DAPs involved in ROS system of the three crucial stages were identified, suggesting that ROS system may play stage-specific roles in different stages through integrating with the baseline metabolism pathways. Besides, a stronger ROS accumulation was detected at the stage of MF compared to the other two stages. Observed under a fluorescence inverted microscopy, ROS signals distributed within the conidiospore and ascus. SOD activities serially increased across the three stages and CAT significantly increased in MF compared to the other two stages. Combined with previous studies, we proposed that ROS gradient may control the development guided by environmental stimulus. The finding would help to further understand the biology and impact the big industry of this valuable fungus.

Authors' contributions: Jinlin Guo conceived this study, designed the experimental plan. Xinxin Tong performed data analysis, participated in designing experiment and writing-original draft. Fang Wang prepared samples and participated in data analysis. Han Zhang participated in sample preparation and performed qPCR experiment. Jing Bai performed ROS assay and sample preparing. Qiang Dong and Pan Yue participated in sample preparing and sample processing. Xinyi Jiang, Xinrui Li and Li Wang participated in total RNA extraction, ROS and activities assays. All authors read and approved the final manuscript.

Acknowledgments: This study was supported by the Natural Sciences Foundation of China Science $(81872959,8137392$

\section{References}

1. Lo, H., Hsieh, C., Lin, FY., Hsu TH. 2013. A systematic review of the mysterious caterpillar fungus Ophiocordyceps sinensis in Dong-Chong Xia Cao (Dong Chong Xia Căo) and related bioactive ingredients. Journal of Traditional and Complementary Medicine 3(1): 16-32 DOI org/10.1016/S2225-4110(16)30164-X.

2. Yanqiang Wei, Liang Zhang, Jinniu Wang, Wenwen Wang, NaudiyalNiyati, Yanlong Guo, Xufeng Wang. 2020. Chinese caterpillar fungus (Ophiocordyceps sinensis) in China: Current distribution, trading, and futures under climate change and 
$530 \quad$ overexploitation. Science of The Total Environment 755(1): 142548 DOI org/10.1016/j.scitotenv.2020.142548.

3. Xu J, Huang Y, Chen XX, Zheng SC, Chen P, Mo MH. 2016. The mechanisms of pharmacological activities of Ophiocordyceps sinensis fungi. Phytother Res 30:1572-1583 DOI 10.1002/ptr.5673.

4. Li X, Liu Q, Li W, Li Q, Qian Z, Liu X, Dong C. 2019. A breakthrough in the artificial cultivation of Chinese cordyceps on a large-scale and its impact on science, the economy, and industry. Crit Rev Biotechnol 39(2): 181-191 DOI $10.1080 / 07388551$.

5. Shrestha UB. 2012. Asian medicine: a fungus in decline. Nature 482:35 DOI 10.1038/482035b.

6. Zhang, Xu , Liu, Qun, Zhou, Wei , Li, Ping, Alolga, Raphael N. , Qian, Zhenming, Li, Wenjia , Qi, Lian-Wen , Yin, Xiaojian. 2018. A comparative proteomic characterization and nutritional assessment of naturally- and artificially-cultivated Cordyceps sinensis. Journal of Proteomics 15: 24-35 DOI org/10.1016/j.jprot.2018.03.029.

7. Enhua Xia, D. Y., Jianjun Jiang, Qunjie Zhang, Yuan Liu, Yunlong Liu, Yun Zhang, Haibin Zhang, Cong Shi, Yan Tong, Changhoon Kim, Hua Chen, Yanqiong Peng, Yue Yu, Wei Zhang, Evan E Eichler, Lizhi Gao. 2017. The caterpillar fungus, Ophiocordyceps sinensis, genome provides insights into highland adaptation of fungal pathogenicity. Scientific Reports 7(1): 1806-1817 DOI 10.1038/s41598-017-01869-z.

8. Christos D. Georgiou, Nikolaos Patsoukis, Ioannis Papapostolou, George Zervoudakis. 2006. Sclerotial metamorphosis in filamentous fungi is induced by oxidative stress. Integrative and Comparative Biology 46(6):691-712 DOI org/10.1093/icb/icj034.

9. Liu, Qizheng, Zhao, Zehui, Dong, Hao, Caihong. 2018. Reactive oxygen species induce sclerotial formation in Morchella importuna. Appl Microbiol Biotechnol 102, 7997-8009 DOI org/10.1007/s00253-018-9104-4.

10. Guiqing L, Richou H , Li C. 2019. Artificial Cultivation of the Chinese Cordyceps From Injected Ghost Moth Larvae. Environmental Entomology (5):1-7 DOI 10.1093/ee/nvz099.

11. Miaomiao Lia,b, Qian Menga, Huan Zhanga, Ruoyao Nia, Guiling Zhoua, Yanni Zhaoa,b, Peipei Wua,b, Ruihao Shua,b , Qilian Qina, Jihong Zhanga. 2020. Vegetative development and host immune interaction of Ophiocordyceps sinensis within the hemocoel of the ghost moth larva, Thitarodes xiaojinensis. Journal of Invertebrate Pathology 170:107331 DOI org/10.1016/j.jip.2020.107331.

12. Qilian Qin, G. Z., Huan Zhang, Qian Meng, Jihong Zhang, Hongtuo Wang, Lin Miao, Xuan Li. 2018. Obstacles and approaches in artificial cultivation of Chinese cordyceps. Mycology 9(1): 7-9 DOI 10.1080/21501203.2018.1442132.

13. Pöggeler, S., M. Nowrousian,U.Kück. 2006. Fruiting-Body Development in Ascomycetes, in Growth, Differentiation and Sexuality. Berlin, Heidelberg, Springe. DOI org/10.1007/3-540-28135-5_16.

14. Oda K, Hasunuma K. 1997. Genetic analysis of signal transduction through light-induced protein phosphorylation in Neurospora crassa perithecia. Mol Gen Genet 256:593-601. DOI org/10.1007/s004380050607.

15. Degli Innocenti F, Russo VEA. 1983. Photoinduction of protoperithecia in Neurospora crassa by blue light. Photochem Photobiol, 37:49-51 DOI 10.1111/j.1751-1097.1983.tb04432.x.

16. Busch S, Eckert SE, Krappmann S, Braus GH. 2003. The COP9 signalosome is an essential regulator of development in the filamentous fungus Aspergillus nidulans. Mol Microbiol 49:717-730 DOI 10.1046/j.1365-2958.2003.03612.x.

17. Lara-Ortíz T, Riveros-Rosas H, Aguirre J. 2003. Reactive oxygen species generated by microbial NADPH oxidase NoxA regulate sexual development in Aspergillus nidulans. Mol Microbiol 50:1241-1255 DOI 10.1046/j.1365-2958.2003.03800.x.

18. Yoshida Y, Hasunuma K. 2004. Reactive oxygen species affect photomorphogenesis in Neurospora crassa. J Biol Chem 279:6986-6993 DOI 10.1074/jbc.M310060200.

19. Tatiana A. Belozerskaya, Natalia N. Gessler, Elena P. Isakova, Yulia I. Deryabina.2012. Neurospora crassa Light Signal Transduction Is Affected by ROS. Journal of Signal Transduction 2012(2):791963 DOI 10.1155/2012/791963. 
20. Li X, Wang F, Liu Q, Li QP, Qian Zh, Zhang XL, Li K, Li WJ, Dong CH. 2019. Developmental transcriptomics of Chinese cordyceps reveals gene regulatory network and expression profiles of sexual development-related gene. BMC Genomics 20(1):337 DOI 10.1186/s12864-019-5708-z.

21. P. Krijgsheld, R. Bleichrodt, G.J. van Veluw, F. Wang, W.H. Müller, J. Dijksterhuis, H.A.B. Wösten. 2013. Development in Aspergillus. Stud Mycol 15; 74(1): 1-29 DOI 10.3114/sim0006.

22. Tong X, Zhang H, Wang F, Xue Z , Cao J , Peng C, Guo JL. 2020. Comparative transcriptome analysis revealed genes involved in the fruiting body development of Ophiocordyceps sinensis. PeerJ 8(1):e8379 DOI 10.7717/peerj.8379

23. Gan, Chee Sian, Chong, Poh Kuan, Pham, Trong Khoa , Wright, Phillip C. 2007. Technical, experimental, and biological variations in isobaric tags for relative and absolute quantitation (iTRAQ). Journal of Proteome Research 6(2): 821-827 DOI org/10.1021/pr060474i.

24. Camon Evelyn, Magrane Michele, Barrell Daniel, Lee Vivian, Dimmer Emily, Maslen John, Binns David, Harte Nicola, Lopez Rodrigo, Apweiler Rolf. 2004. The Gene Ontology Annotation (GOA) Database: sharing knowledge in Uniprot with Gene Ontology. Nuclc Acids Research 32(suppl_1): D262-D266 DOI org/10.1093/nar/gkh021.

25. Gerlich M , Neumann S. 2000. KEGG: kyoto encyclopedia of genes and genomes. Nuclc Acids Research 28(1):27-30 DOI 10.1093/nar/27.1.29.

26. Yanhong, Wei, Jie, Zhang, Shenhui, Xu, Xin, Peng, Xia, Yan. 2018. Controllable oxidative stress and tissue specificity in major tissues during the torpor-arousal cycle in hibernating Daurian ground squirrels. Open Biology. 8: 180068 DOI 10.1098/rsob.180068.

27. Xin Zhong, L. G., Haizhen Wang, Danhong Lian, Yimei Zheng, Sha Zhou, Wei Zhou, Jinlei Gu, Guren Zhang, XinLiu. 2018. Profile of Ophiocordyceps sinensis transcriptome and differentially expressed genes in three different mycelia, Sclerotium and fruiting body developmental stages. Fungal Biology 122(10): 943-951 DOI 10.1016/j.funbio.2018.05.011.

28. Silar P, Lalucque H, Haedens V, Zickler D, Picard M. 2001. EF1A controls ascospore differentiation through elevated accuracy, but controls longevity and fruiting body formation through another mechanism in Podospora anserina. Genetics 158:1477-1489 DOI 10.1017/S0016672301005183

29. ANNE-SOPHIE DIELEN, SALOUA BADAOUI , THIERRY CANDRESSE, SYLVIE GERMAN-RETANA1. 2010. The ubiquitin/26S proteasome system in plant-pathogen interactions: a never-ending hide-and-seek game. Molecular Plant Pathology (2): 293-308 DOI 10.1111/j.1364-3703.2010.00673.x.

30. M.L. Zhao, J.S. Huang, M.H. Mo and K.Q. Zhan. 2005. A potential virulence factor involved in fungal pathogenicity: Serinelike protease activity of nematophagous fungus Clonostachys rosea. Fungal diversity 19:217-234.

31. Zhang Y, Liu X, Wang M. 2008. Cloning, expression, and characterization of two novel cuticle-degrading serine proteases from the entomopathogenic fungus Cordyceps sinensis. Research in Microbiology 159(6):462-469 DOI 10.1016/j.resmic.2008.04.004.

32. Krappmann S, Braus GH. 2003. Deletion of Aspergillus nidulans are using a novel blaster module that combines ET cloning and marker rescue. Mol Genet Genomics 268:675-683 DOI 10.1007/s00438-002-0789-8.

33. Eckert SE, Hoffmann B, Wanke C, Braus GH. 1999. Sexual development of Aspergillus nidulans in tryptophan auxotrophic strains. Arch Microbiol 172:157-166.

34. EckertSE, KüblerE, HoffmannB, BrausGH. 2000. The tryptophan synthase-encoding trpB gene of Aspergillus nidulans is regulated by the cross-pathway control system. Mol Gen Genet 263:867-876 DOI 10.1007/s004380000250.

35. Busch S, Hoffmann B, Valerius O, Starke K, Düvel K, Braus GH. 2001. Regulation of the Aspergillus nidulans hisB gene by histidine starvation. Curr Genet 38:314-322 DOI 10.1007/s002940000171.

36. Christine M Roche , Harvey W Blanch, Douglas S Clark , N Louise Glass. 2013. Physiological Role of Acyl Coenzyme A 
612 Synthetase Homologs in Lipid Metabolism in Neurospora crassa. Eukaryotic Cell 12(9): 1244-1257 DOI 10.1128/EC.00079-

61313.

614 37. Peraza-Reyes L, Berteaux-Lecellier V. 2013. Peroxisomes and sexual development in fungi. Frontiers in Physiology 4:244 615 DOI: 10.3389.

616 38. Berteaux-Lecellier V, Picard M, Thompson-Coffe C, Zickler D, Panvier-Adoutte A, Simonet JM. 1995. A nonmammalian 617 homolog of the PAF1 gene (Zellweger syndrome) discovered as a gene involved in caryogamy in the fungus Podospora 618 anserina. Cell 81:1043-1051 DOI 10.1016/s0092-8674(05)80009-1.

619 39. Scherer M, Wei H, Liese R, Fischer R. 2002. Aspergillus nidulans catalase-peroxidase gene (cpeA) is transcriptionally induced

40. Holliday JC, Cleaver M. 2008. Medicinal value of the caterpillar fungi species of the genus Cordyceps (Fr.) link (Ascomycetes). Areview. Int J Med Mushrooms 10:219-234 DOI 10.1615/IntJMedMushr.v10.i3.30.

41. Otani M, Tabata J, Ueki T, Sano K, Inouye S. 2001. Heat-shockinduced proteins from Myxococcus xanthus. J Bacteriol 183:6282-6287 DOI 10.1126/science.aad2001.

42. Barbara S. Polla. 1991. Heat shock proteins in host-parasite interactions. Parasitology Today 7(3):A38 DOI 10.1016/0169-4758(91)90028-M.

43. Fillinger S, Chaveroche MK, Shimizu K, Keller N, d'Enfert C. 2002. cAMP and ras signalling independently control spore germination in the filamentous fungus Aspergillus nidulans. Mol Microbiol 44:1001-1016 DOI 10.1046/j.13652958.2002.02933.x.

44. Yang Q, Poole SI, Borkovich KA. 2002.G-protein $\beta$ subunit required for sexual and vegetative development and maintenance of normal Ga protein levels in Neurospora crassa. Eukaryot Cell 1:378-390 DOI 10.1128/ec.1.3.378-390.2002.

45. Kothe GO, Free SJ. 1998. The isolation and characterization of nrc-1 and nrc-2, two genes encoding protein kinases that control growth and development in Neurospora crassa. Genetics 149:117-130.

46. Duarte M, Videira A. 2010. Effects of mitochondrial complex III disruption in the respiratory chain of Neurospora crassa. Molecular Microbiology 72(1):246-258 DOI 10.1111/j.1365-2958.2009.06643.x.

47. Stamm I, Lottspeich F, Plaga W. 2005. The pyruvate kinase of Stigmatella aurantiaca is an indole binding protein and essential for development. Molecular Microbiology 56(5):1386-1395 DOI 10.1111/j.1365-2958.2005.04640.x.

48. Otani M, Tabata J, Ueki T, Sano K, Inouye S. 2001.Heat-shock induced proteins from Myxococcus xanthus. J Bacteriol 183:6282-6287 DOI 10.1128/JB.183.21.6282-6287.2001.

49. Yoon JJ, Munir E, Miyasou H, Hattori T, Terashita T, Shimada M. 2002. A possible role of the key enzymes of the glyoxylate and gluconeogenesis pathways for fruit-body formation of the wood-rotting basidiomycete Flammulina velutipes. Mycoscience 43:327-332 DOI org/10.1007/S102670200048.

50. Kun Feng, Lan-ying Wang, Dong-jiang Liao, Xin-peng Lu, De-jun Hu, Xiao Liang, Jing Zhao, Zi-yao Mo, Shao-ping Li. 2017. Potential molecular mechanisms for fruiting body formation of Cordyceps illustrated in the case of Cordyceps sinensis. Mycology 8(4):1-28 DOI 10.1080/21501203.2017.1365314.

51. Kulkarni RK.1990. Mannitol metabolism in Lentinus edodes, the Shiitake mushroom. Appl Environ Microbiol 56:250-253 DOI 10.1128/AEM.56.1.250-253.1990.

52. Wannet WJB, Hermans JHM, Van Der Drift C, Op Den Camp HJM. 2000. HPLC detection of soluble carbohydrates involved in mannitol and trehalose metabolism in the edible mushroom Agaricus bisporus. J Agric Food Chem 48:287-291 DOI 10.1021/jf990596d.

53. Muraguchi H, Kamada T. 2000. A mutation in the eln2 gene encoding a cytochrome P450 of Coprinus cinereus affects mushroom morphogenesis. Fungal Genetics \& Biology 29(1):49-59 DOI 10.1006/fgbi.2000.1184. 
653

654

655

656

657

658

659

660

661

662

663

664

665

666

667

668

669

670

671

672

673

674

675

676

677

678

679

680

681

682

683

684

685

686
54. Fassler J S, West A H. 2013. Histidine Phosphotransfer Proteins in Fungal Two-Component Signal Transduction Pathways. Eukaryotic Cell 12(8):1052-1060 DOI 10.1128/EC.00083-13.

55. Dirschnabel DE, Nowrousian M, Cano-Domínguez N, Aguirre J, Teichert I, Kück U. 2014. New insights into the roles of NADPH oxidases in sexual development and ascospore germination in Sordaria macrospora. Genetics 196(3):729-744 DOI 10.1534/genetics.113.159368.

56. Malagnac F, Lalucque H, Lepere G, Silar P. 2004. Two NADPH oxidase isoforms are required for sexual reproduction and ascospore germination in the filamentous fungus Podospora anserina. Fungal Genet Biol 41:982-997 DOI org/10.1016/j.fgb.2004.07.008.

57. Oier Etxebeste, Erika Herrero-García, Marc S. Cortese, Aitor Garzia, Elixabet Oiartzabal-Arano, Vivian de los Ríos, Unai Ugalde, Eduardo A. Espeso. 2017. GmcA Is a putative glucose-methanol-choline oxidoreductase required for the induction of asexual development in Aspergillus nidulans. PLoS ONE 7: e40292 DOI 10.1371/journal.pone.0040292.

58. Yueming Qian, Sanjay Banerjee, Craig E. Grossman, Wendy Amidon, Gyorgy Nagy, Maureen Barcza, Brian Niland, David R. Karp, Frank A. Middleton, Katalin Banki, Andras Per. 2008. Trsansaldolase deficiency influences the pentose phosphate pathway, mitochondrial homoeostasis and apoptosis signal processing. Biochemical Journal 415(1):123-134 DOI 10.1042/BJ20080722.

59. Tong Sen-Miao, Chen Ying, Zhu Jing, Ying Sheng-Hua, Feng Ming-Guang. 2016. Subcellular localization of five singular WSC domain-containing proteins and their roles in Beauveria bassiana responses to stress cues and metal ions. Environmental Microbiology Reports 8(2):295-304 DOI 10.1111/1758-2229.12380.

60. Giovanni Gadda, Kevin Francis, Merid Belaineh. 2007. The Mechanism of 2-Nitropropane Dioxygenase: a Model for Flavin Semiquinone Intermediates in Enzymatic Catalysis. Experimental Biology (Part I) 21, 5: A272-A272 DOI 10.1096/fasebj.21.5.A272.

61. Minou N, Kück Ulrich. 2010. Comparative gene expression analysis of fruiting body development in two filamentous fungi. Fems Microbiology Letters (2): 328-335 DOI 10.1111/j.1574-6968.2006.00192.x.

62. Bang, Y.-J., Oh, M. H., Choi, S. H. 2012. Distinct characteristics of two 2-Cys peroxiredoxins of Vibrio vulnifcus suggesting differential roles in detoxifying oxidative stress. Journal of Biological Chemistry 287, 42516-42524 DOI 10.1074/jbc.M112.421214.

63. Arwa Alharbi, Seham M Rabadi, Maha Alqahtani, Dina Marghani, Madeline Worden, Zhuo Ma, Meenakshi Malik, Chandra Shekhar Bakshi. 2019. Role of peroxiredoxin of the AhpC/TSA family in antioxidant defense mechanisms of Francisella tularensis. PLoS One 14(3): e0213699. Tularensis DOI 10.1371/journal.pone.0213699.

64. Gessler N N , A. A. Aver' yanov, Belozerskaya T A. 2007. Reactive oxygen species in regulation of fungal development. Biochemistry 72(10): 1091-1109 DOI 10.1134/s0006297907100070.

65. Diaz A, Munoz-Clares RA, Rangel P, Valdes VJ , Hansberg W. 2005. Functional and structural analysis of catalase oxidized by singlet oxygen. Biochimie 87(2):205-214 DOI 10.1016/j.biochi.2004.10.014. 


\section{Figure 1}

O. sinensis samples collection for proteome sequencing.

Different developmental stages of $O$. sinensis. ST: sclerotium (mummified larva) before stroma development; PR: sclerotium with initial stroma (stroma $<1 \mathrm{~cm}$ ); MF: fruiting body with mature perithecia, ascus and ascospores.

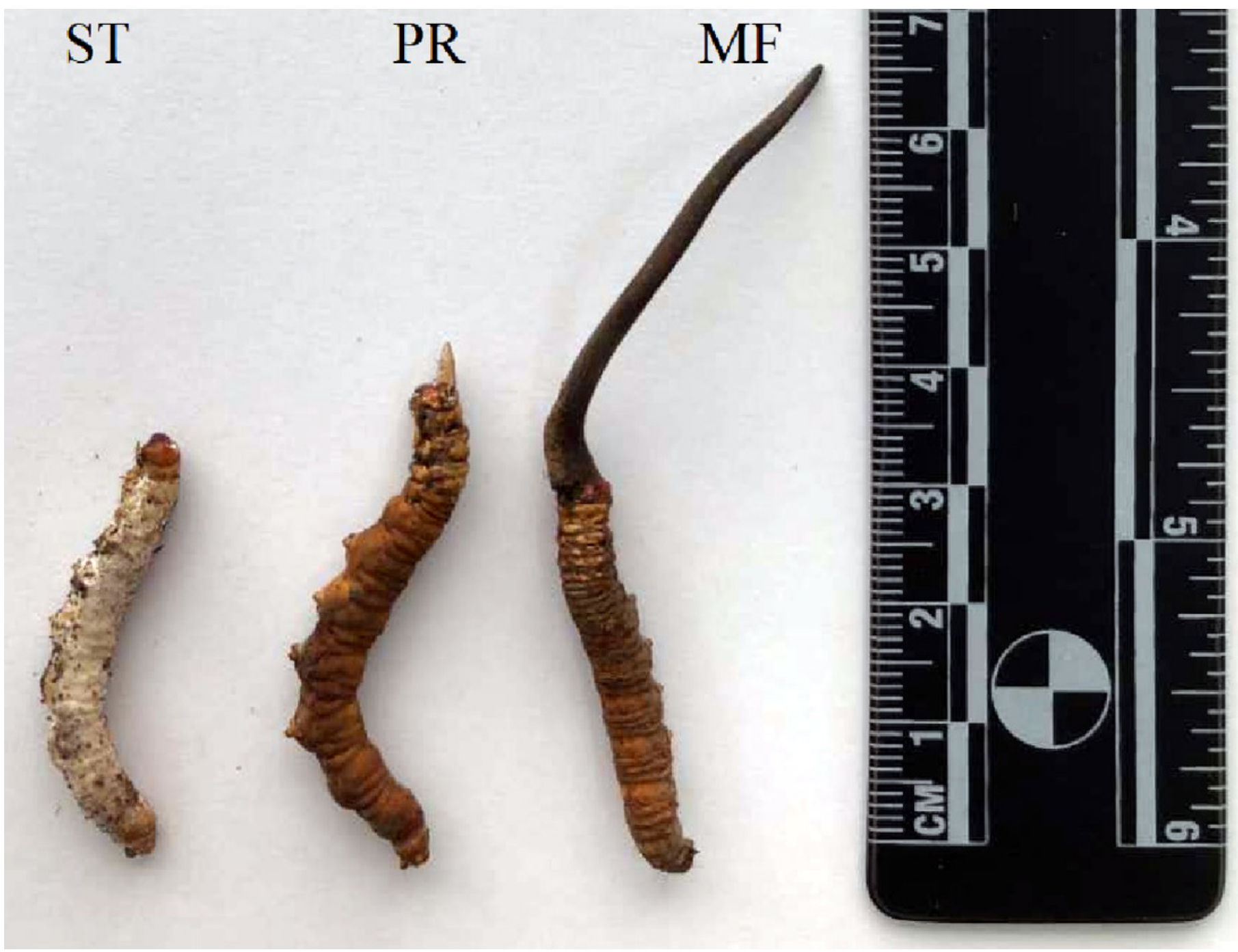




\section{Figure 2}

Analysis of differentially accumulated proteins (DAPs) between different growth stages in O. sinensis.

A. Venn diagram of DAPs comparing between different growth stages from 0 . sinensis. ST: sclerotium (mummified larva) before stroma development; PR: sclerotium with initial stroma (stroma $<1 \mathrm{~cm}$ ); MF: fruiting body with mature perithecia, ascus and ascospores. $\mathrm{B}$. The number of DAPs is shown on the top of histograms. statistics of DAPs from 0 . sinensis between different growth stages.
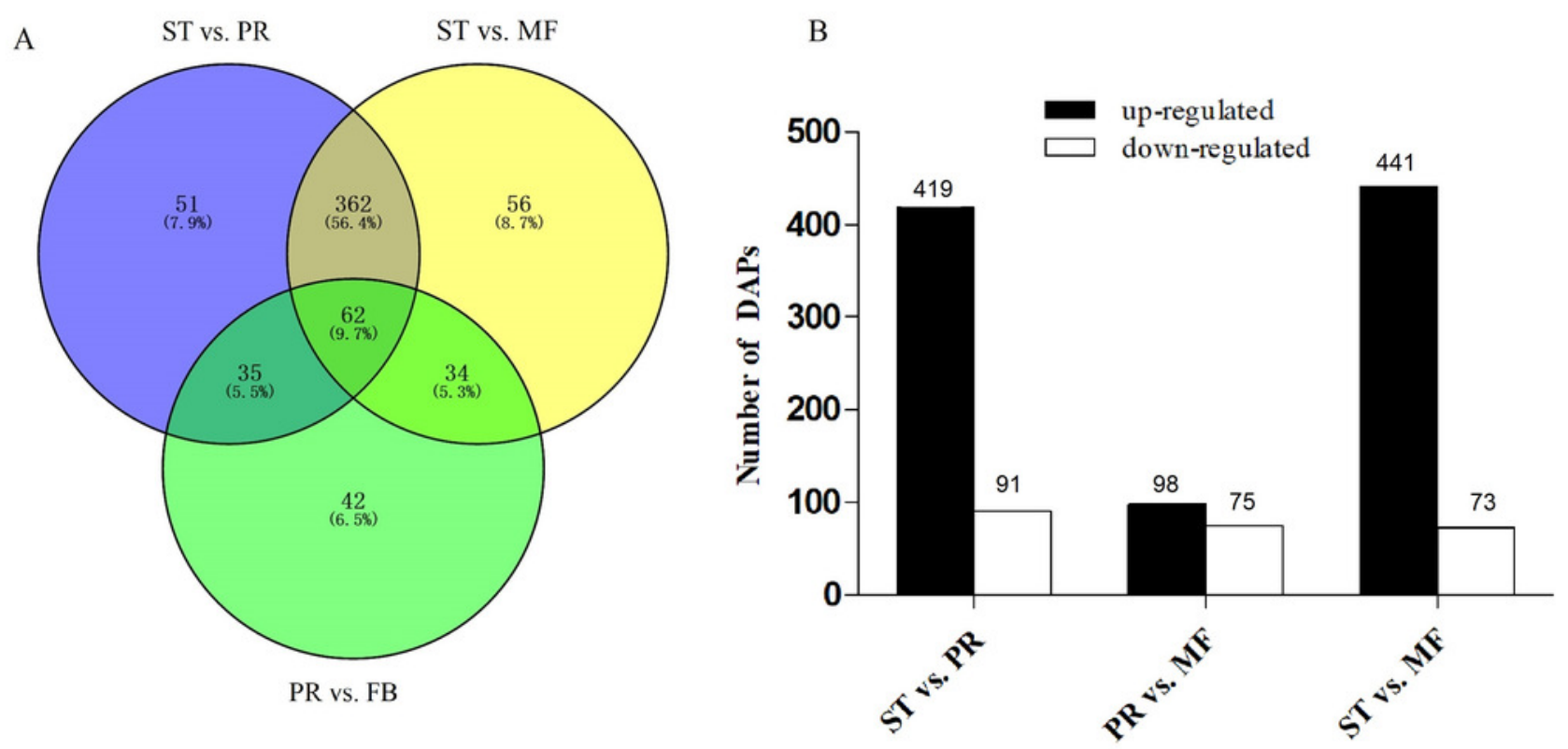


\section{Figure 3}

The most enriched GO functional classification of DAPs between different growth stages in 0 . sinensis.

The most enriched GO functional classification of DAPs between different growth stages. Only the significant GO terms $(p<0.005)$ were shown. X-axes represent the enrichment score $(-$ Log10 P-value) of top GO terms enriched among DAPs. The blue bars represent biological processes; the orange bars represent cellular components; the green bars represent molecular functions. ST: sclerotium (mummified larva) before stroma development; PR: sclerotium with initial stroma (stroma $<1 \mathrm{~cm}$ ); MF: fruiting body with mature perithecia, ascus and ascospores. 
A

ST vs. PR

ribonucleoside triphosphate metabolic..

purine ribonucleoside triphosphate.

amide transport

peptide transport

amide biosynthetic process

translation

peptide biosynthetic process

peptide metabolic process

cellular amide metabolic process

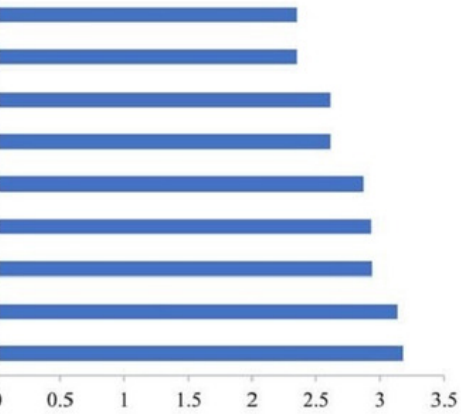

protein-DNA complex

mitochondrial protein complex

nucleosome

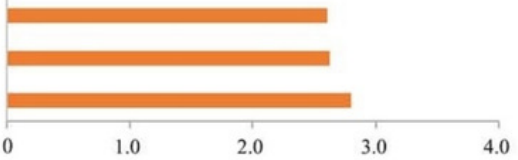

structural molecule activity

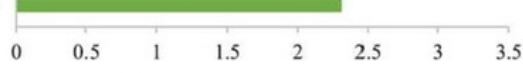

B

PR vs. MF

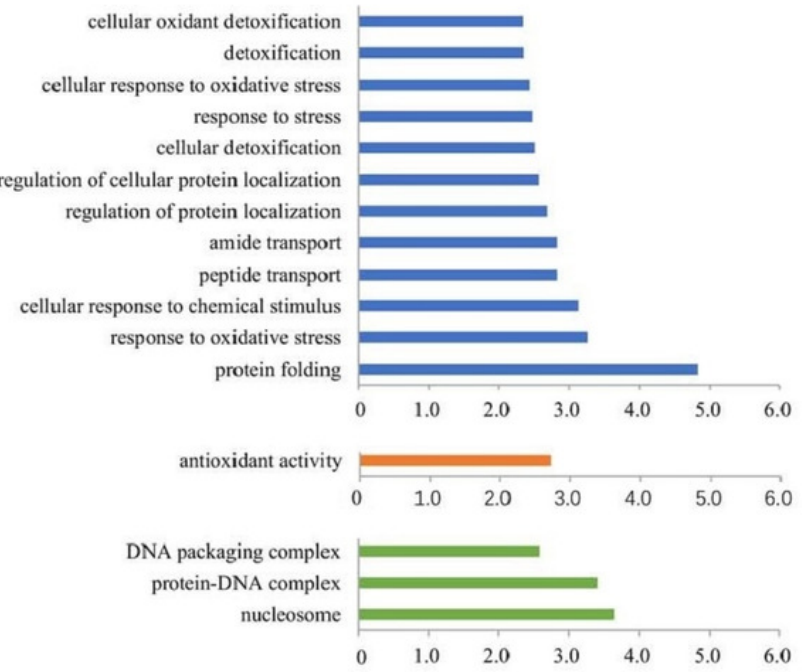

C

\section{ST vs. MF}

protein metabolic process

generation of precursor metabolites and energy

amide biosynthetic process

translation

peptide biosynthetic process

cellular amide metabolic process

peptide metabolic process
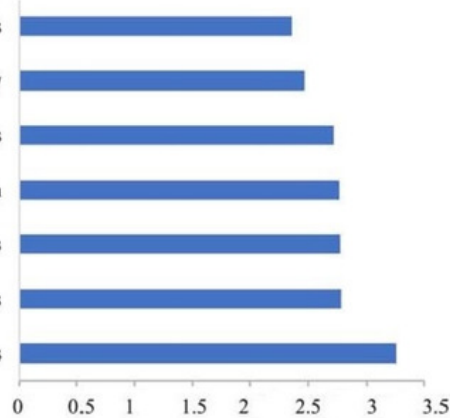

inner mitochondrial membrane protein complex

extracellular region

mitochondrial membrane part

cytosolic part

mitochondrial protein complex
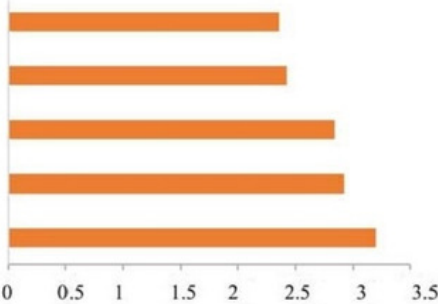
Figure 4

The enriched KEGG pathways of DAPs between different growth stages in $O$. sinensis.

$X$-axes represent the enrichment score (-Log10 P-value) of top GO terms enriched among DEGs. ST: sclerotium (mummified larva) before stroma development; PR: sclerotium with initial stroma (stroma $<1 \mathrm{~cm}$ ); MF: fruiting body with mature perithecia, ascus and ascospores. 


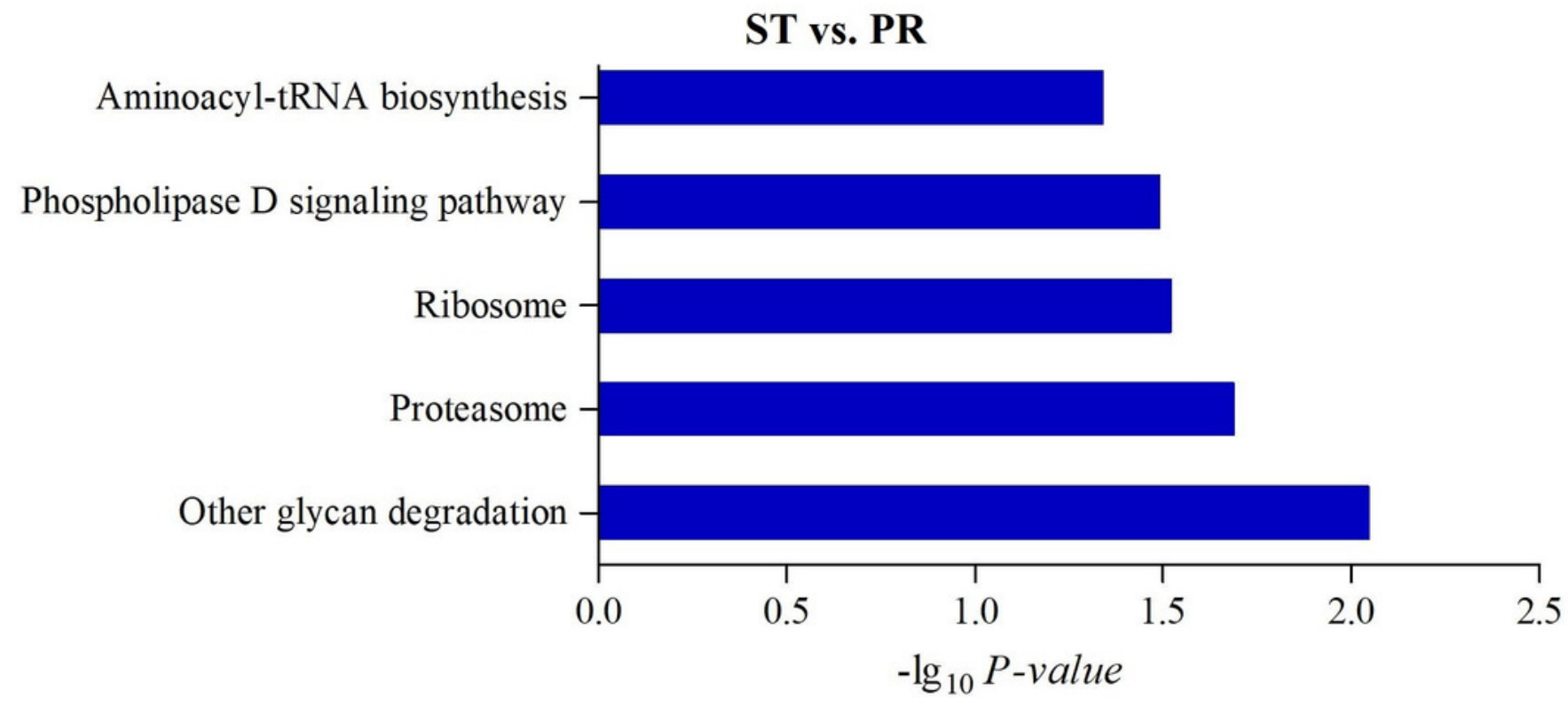

PR vs. MF

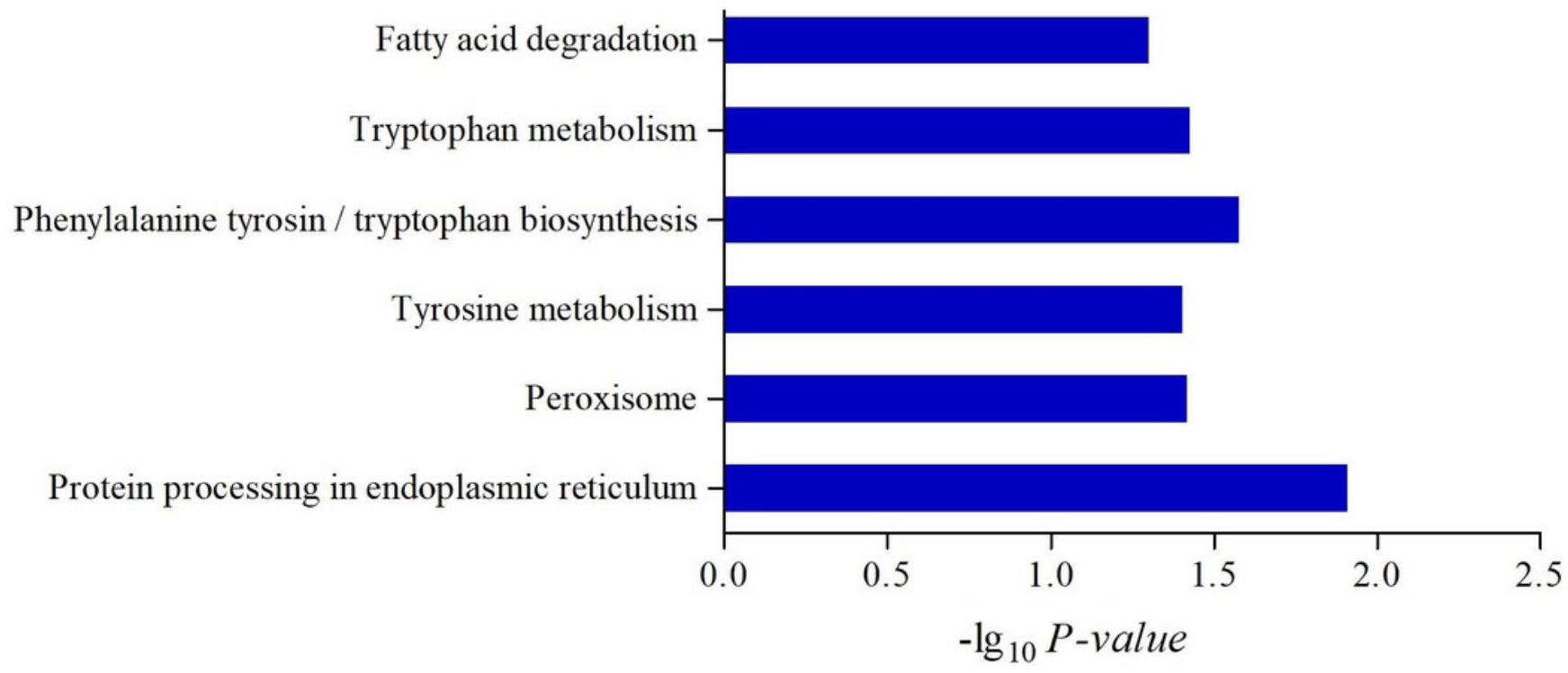

ST vs. MF

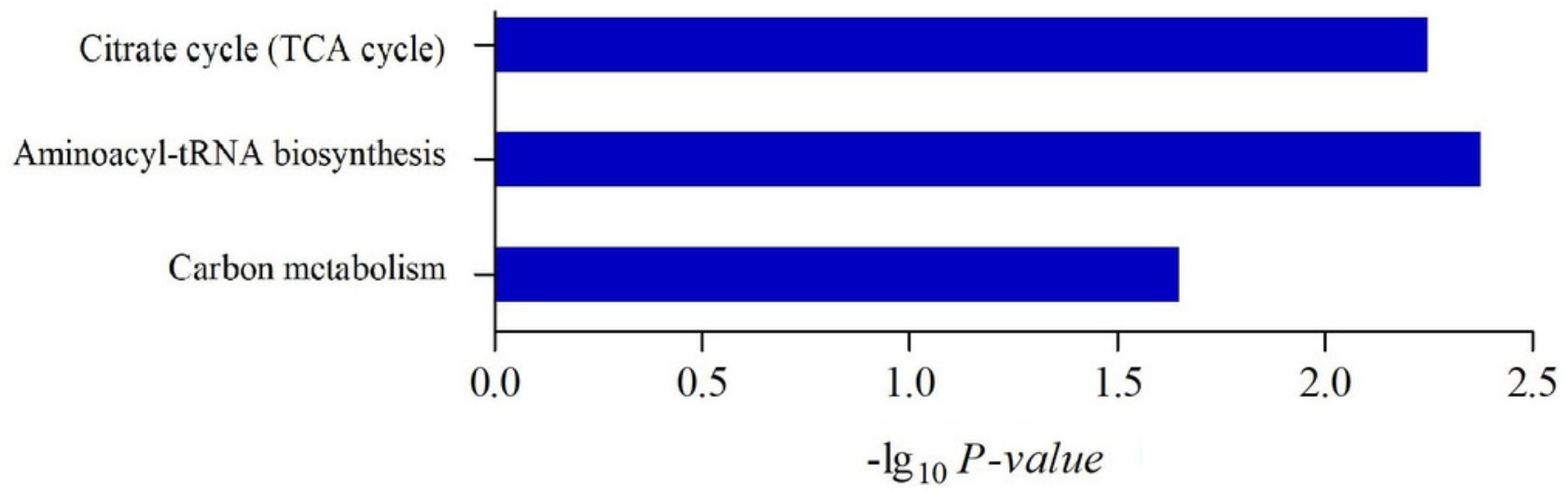




\section{Figure 5}

Clustering of reactive oxygen system (ROS) related DAPs expression profiles across the three growth stages in 0 . sinensis.

A-D. Four protein clusters with different expression patterns. Overlaying curves of all ROS related DAPs within the cluster were shown. E. The heat map reveals relative abundance of these ROS-related DAPs in different growth stages. ST: sclerotium (mummified larva) before stroma development; PR: sclerotium with initial stroma (stroma $<1 \mathrm{~cm}$ ); MF: fruiting body with mature perithecia, ascus and ascospores. 

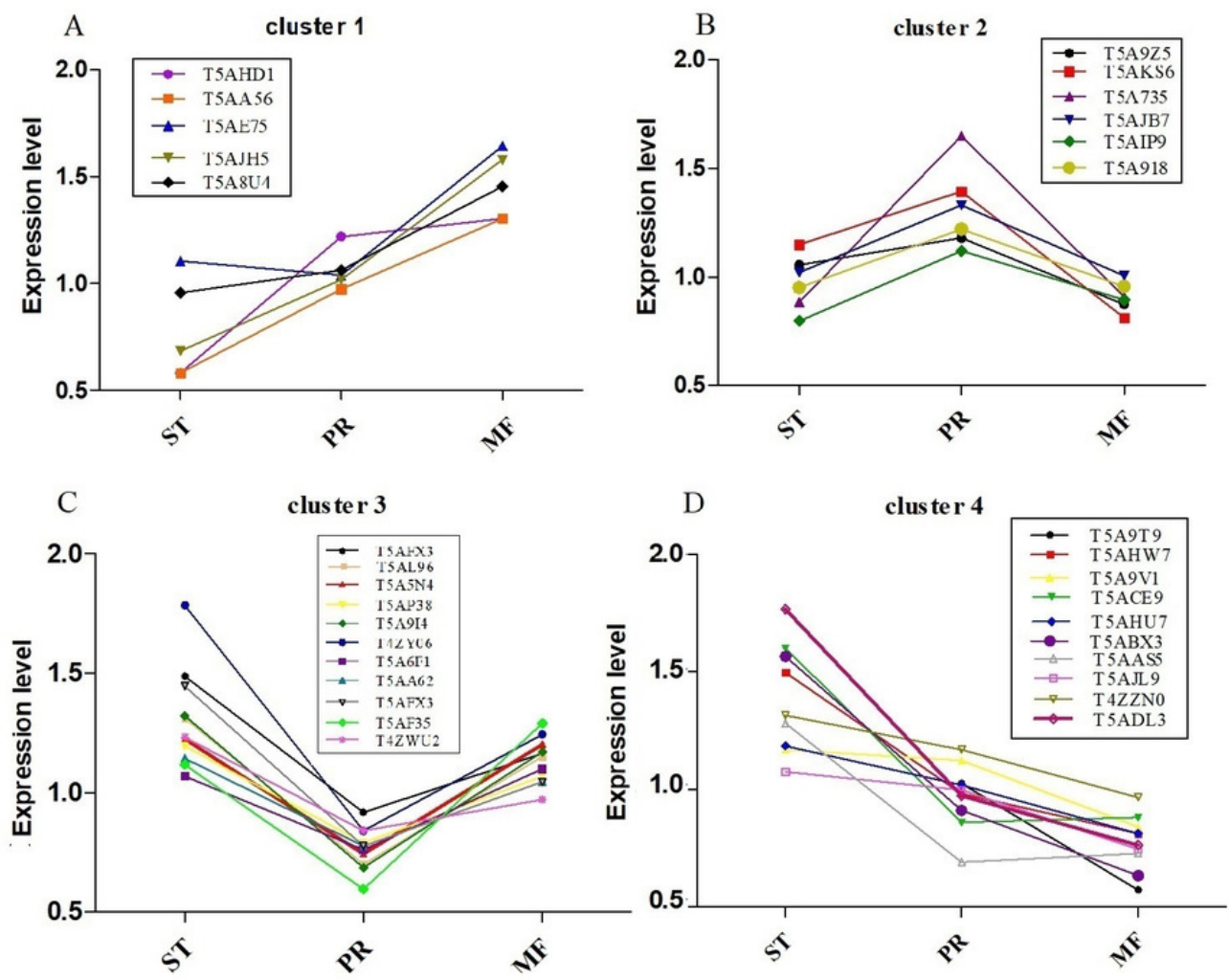

$\mathbf{E}$
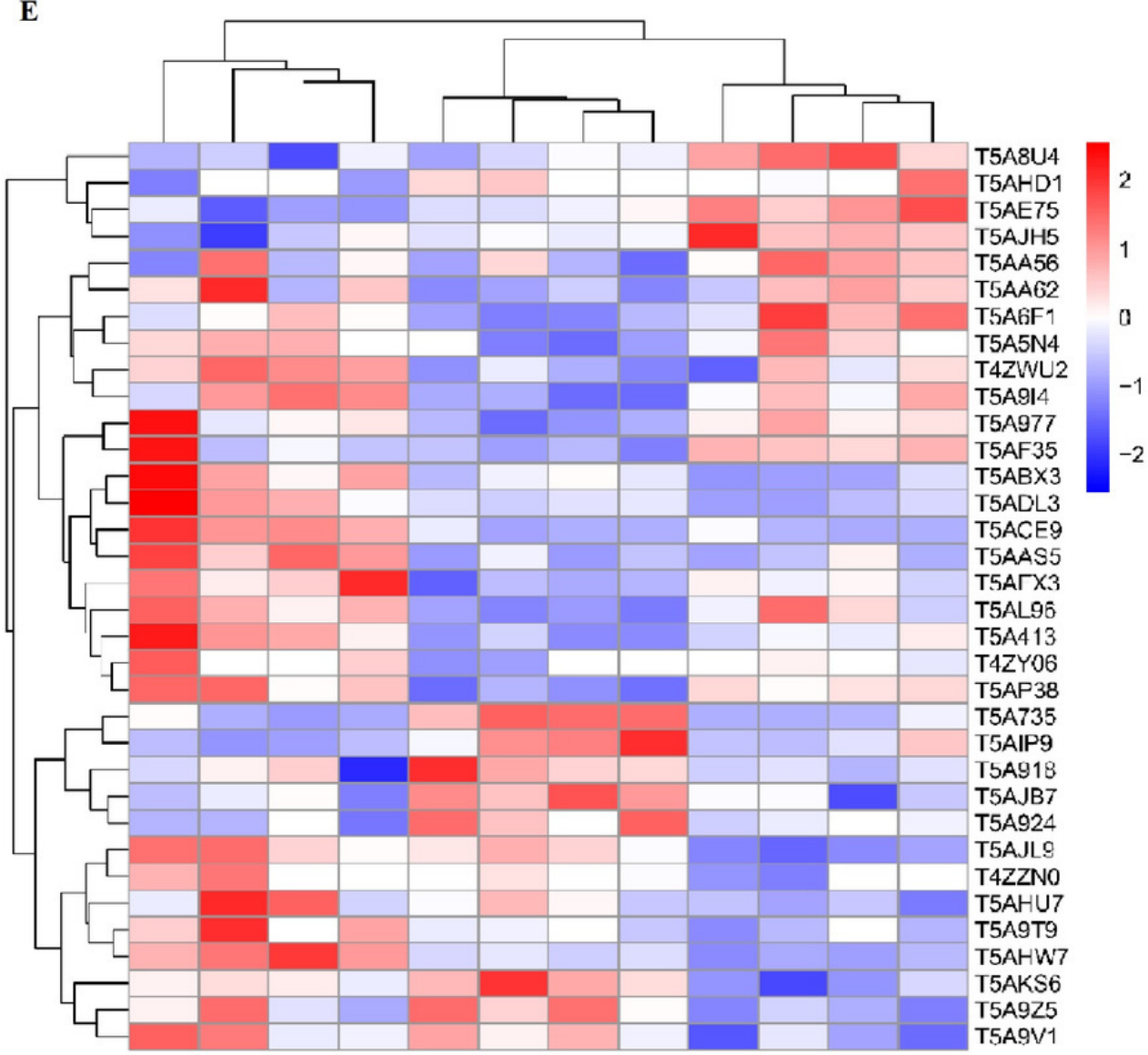

ST-1 ST-3 ST-2 ST-4 PR-4 PR-1 PR-2 PR-3 MF-3 MF-1 MF-2 MF-4 
Figure 6

qRT-PCR validation of the genes encoding for the DAPs.

A. Bars represent the fold change in expression of each candidate gene identified in ST relative to PR. B. Bars represent the fold change in expression of each candidate gene identified in PR relative to MF. Orange bars represent $q R T$-PCR result (2 $\left.\square^{\Delta \Delta C t}\right)$. Error bars indicate the standard error. Blue bars represent the protein-seq results . 18sRNA was the internal reference. ST: sclerotium (mummified larva) before stroma development; PR:

sclerotium with initial stroma (stroma $<1 \mathrm{~cm}$ ); MF: fruiting body with mature perithecia, ascus and ascospores.
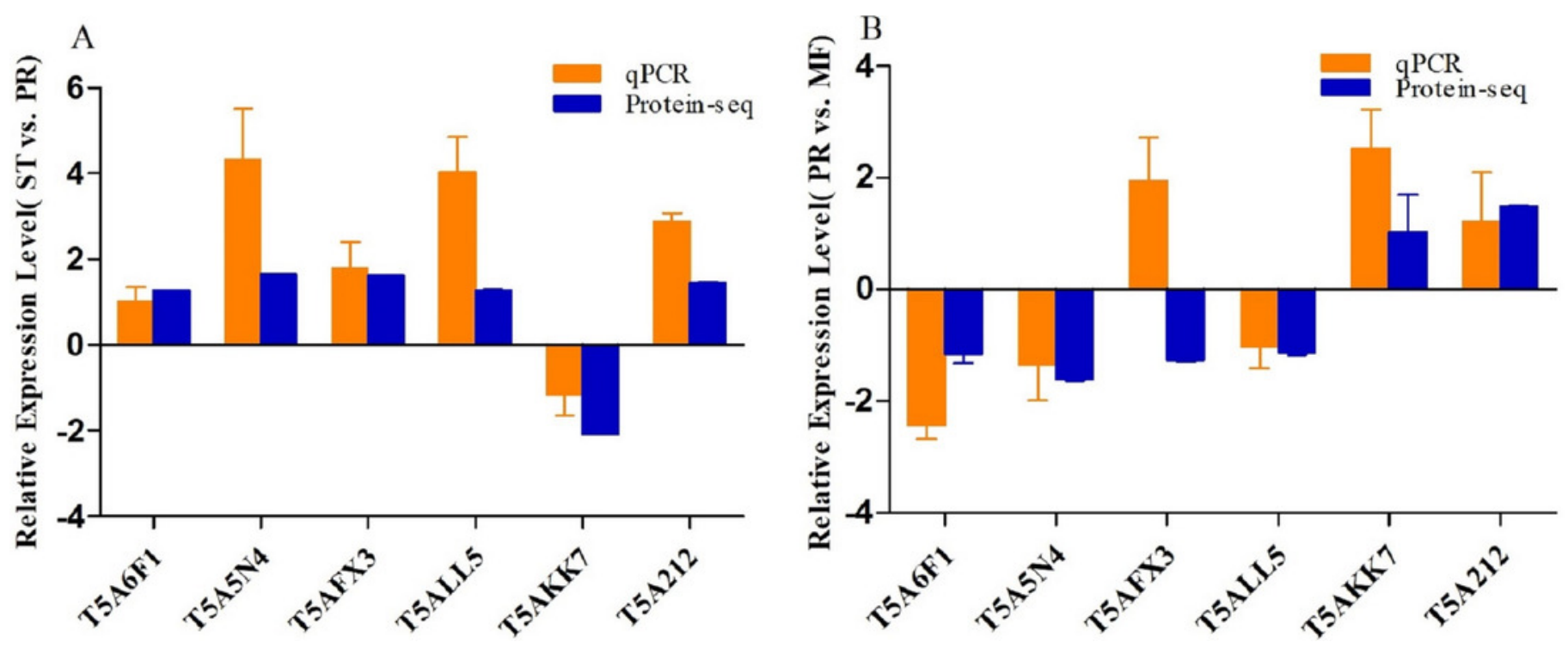


\section{Figure 7}

ROS accumulation in samples of different growth stages of $O$. sinensis.

ST: sclerotium (mummified larva) before stroma development; PR: sclerotium with initial stroma (stroma $<1 \mathrm{~cm}$ ); MF: fruiting body with mature perithecia, ascus and ascospores. Error bars indicate the standard error. Different letters indicate statistically difference between the comparisons, a: $p<0.001$ (MF relative to ST); $\mathrm{b}: p<0.001$ (MF relative to PR).
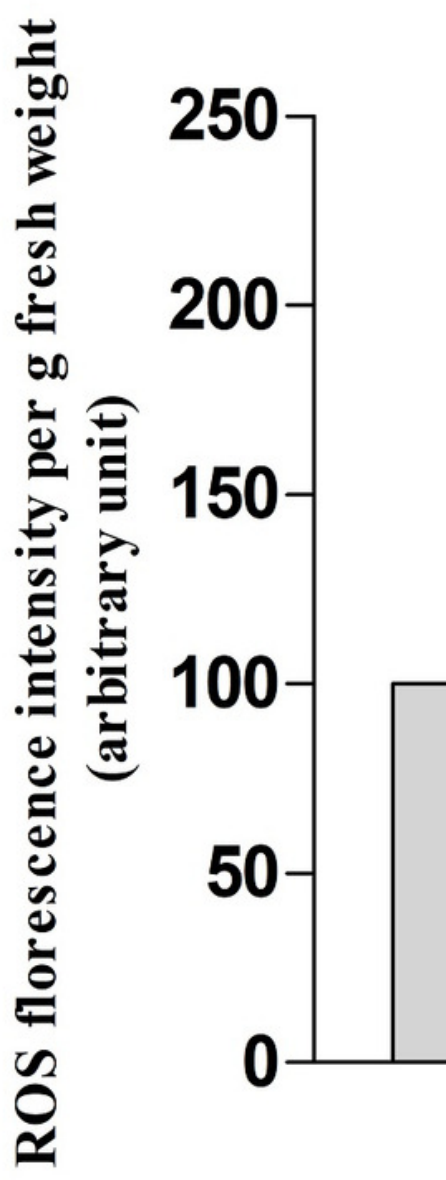


\section{Figure 8}

ROS measurement via DCFH-DA probe detection in O. sinensis.

A. Hypha was detected by $5 \mu \mathrm{M} \mathrm{H} 2 \mathrm{DCF}-\mathrm{DA}$ for $20 \mathrm{~min}$ at $37^{\circ} \mathrm{C}$. B. Fruiting body was detected by $5 \mu \mathrm{M} \mathrm{H} 2 \mathrm{DCF}-\mathrm{DA}$ for $20 \mathrm{~min}$ at $37^{\circ} \mathrm{C}$. Scale bar represents $30 \mu \mathrm{m}$.

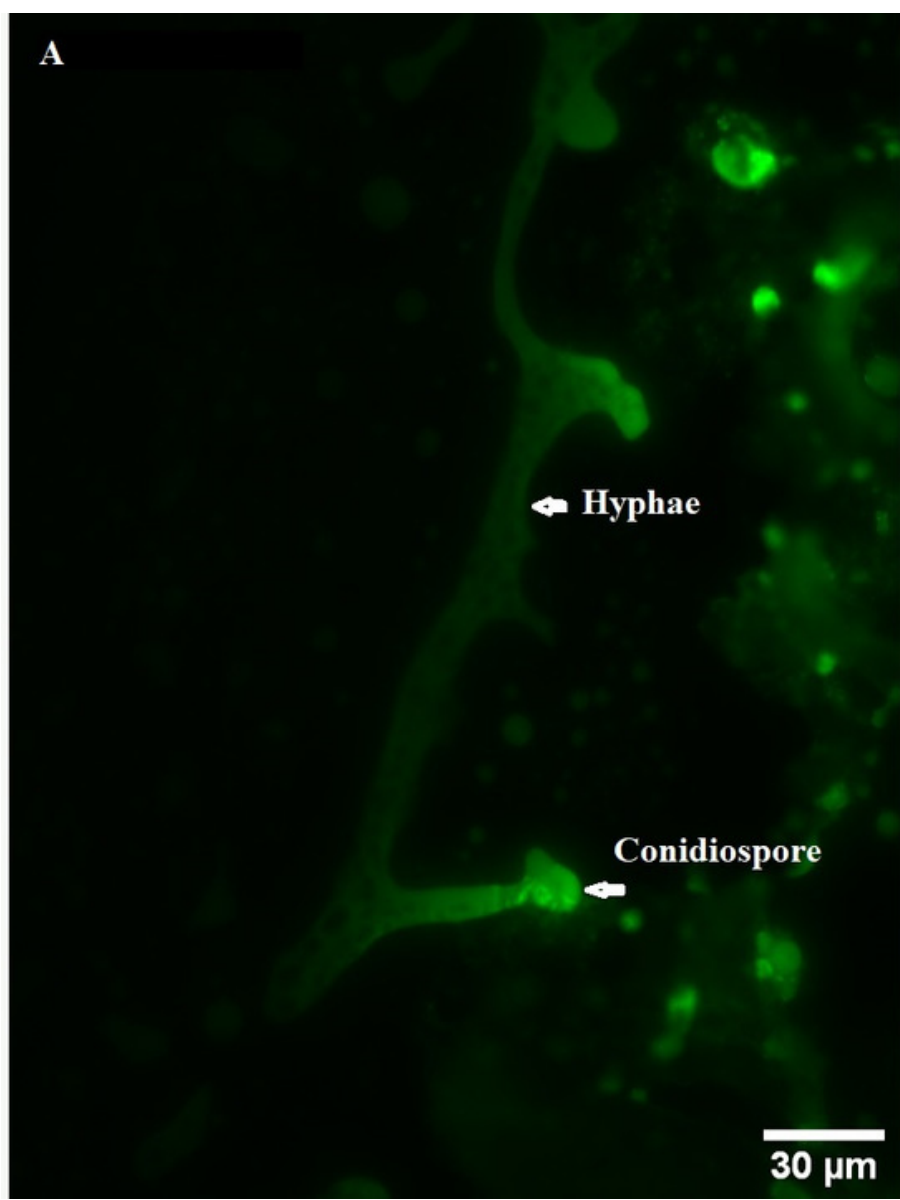




\section{Figure 9}

CAT and SOD activities in samples of different stages in 0 . sinensis.

A. CAT activity in samples at different stages. a: $p<0.01$, MF relative to ST; $b: p<0.01$, MF relative to PR. B. SOD activity in samples at different stages. $a: p<0.01, P R$ relative to ST; $b$ : $p<0.001$, MF relative to ST; a:p $<0.05$, MF relative to PR. ST: sclerotium (mummified larva) before stroma development; PR: sclerotium with initial stroma (stroma $<1 \mathrm{~cm}$ ); MF: fruiting body with mature perithecia, ascus and ascospores. Error bars indicate the standard error. Different letters indicate statistically difference between the comparisons.
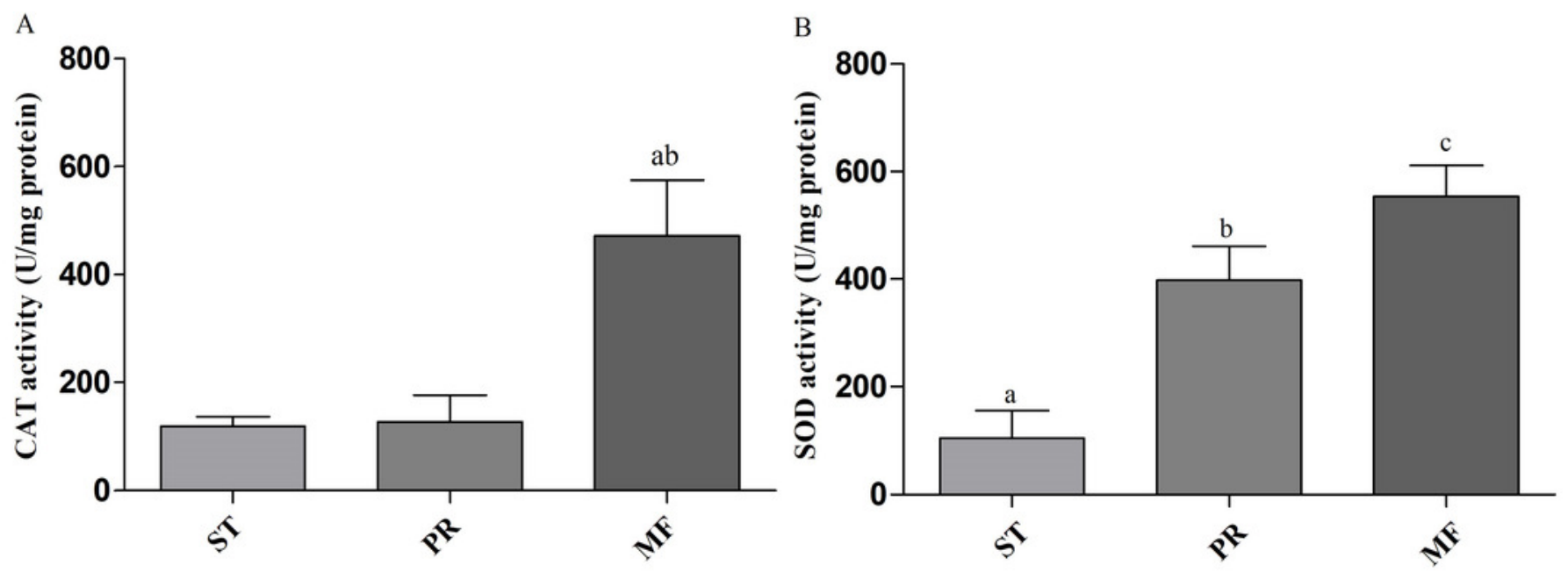


\section{Table $\mathbf{1}$ (on next page)}

A Number of spectra, peptide and protein identified by iTRAQ.

ST: The mummified larvae coated with mycelia before stroma development; PR: The samples of stroma with lengths $<1 \mathrm{~cm}$; MF: the fruiting body with mature ascus and ascospores. 
1 Table1. A Number of spectra, peptide and protein identified by iTRAQ

\begin{tabular}{lllllll}
\hline & Total spectra & PSM & Unique spectra & Peptide & Unique peptide & Protein group \\
\hline ST & 470465 & 60770 & 57731 & 25954 & 25114 & 1324 \\
PR & 472920 & 46426 & 42031 & 18563 & 17887 & 1257 \\
MF & 518917 & 46426 & 42031 & 20660 & 19904 & 1275 \\
\hline
\end{tabular}

2

3

4

5

6

7

8

9

10

11

12

13

14

15

16

17

18

19

20

21

22

23

24

25

26

27

28

29

30

31

32

33

34

35

36 


\section{Table 2 (on next page)}

Hierarchical clustering analysis of oxidation-reduction related DAPs among the all comparisons.

ST: The mummified larvae coated with mycelia before stroma development; PR: The samples of stroma with lengths $<1 \mathrm{~cm}$; MF: the fruiting body with mature ascus and ascospores. 
1 Table 2 Hierarchical clustering analysis of oxidation-reduction related DAPs among the all comparisons Cluster1

\begin{tabular}{|c|c|c|c|c|c|c|c|}
\hline $\begin{array}{l}\text { Protein } \\
\text { ID }\end{array}$ & ST vs. PR & p-value & PR vs. MF & p-value & ST vs. MF & p-value & Annotation \\
\hline T5AHD1 & 0.47 & 0.008 & 0.94 & 0.797 & 0.45 & 0.131 & $\begin{array}{l}\text { Electron transport } \\
\text { protein }\end{array}$ \\
\hline T5AA56 & 1.13 & 0.433 & 0.75 & 0.026 & 0.85 & 0.224 & $\begin{array}{l}\text { Aldehyde } \\
\text { dehydrogenase } \\
\text { domain protein }\end{array}$ \\
\hline T5AE75 & 0.66 & 0.050 & 0.63146 & 0.0033 & 0.42 & 0.001 & $\begin{array}{l}\text { Pyridine } \\
\text { nucleotide- } \\
\text { disulfide } \\
\text { oxidoreductase }\end{array}$ \\
\hline T5AJH5 & 0.68 & 0.158 & 0.64456 & 0.021 & 0.44 & 0.016 & $\begin{array}{l}\text { Superoxide } \\
\text { dismutase }\end{array}$ \\
\hline T5A8U4 & 0.90 & 0.345 & 0.73109 & 0.006 & 0.66 & 0.006 & Bli-3 \\
\hline
\end{tabular}

\begin{tabular}{|c|c|c|c|c|c|c|c|}
\hline Cluster 2 & & & & & & & \\
\hline $\begin{array}{l}\text { Protein } \\
\text { ID }\end{array}$ & ST vs. PR & p-value & PR vs. MF & p-value & ST vs. MF & p-value & Annotation \\
\hline T5A9Z5 & 0.89 & $\begin{array}{r}0.280580 \\
1\end{array}$ & 1.35 & 0.005 & 1.21 & 0.092 & $\begin{array}{l}\text { Acetohydroxy acid } \\
\text { isomeroreductase }\end{array}$ \\
\hline T5AKS6 & 0.82 & 0.067688 & 1.72 & 0.005 & 1.42 & 0.009 & $\begin{array}{l}\text { Formate } \\
\text { dehydrogenase }\end{array}$ \\
\hline T5A735 & 0.54 & $\begin{array}{r}0.000981 \\
6\end{array}$ & 1.82 & 0.0004 & 0.97 & 0.841 & Cytochrome P450 \\
\hline T5AJB7 & 0.77 & $\begin{array}{r}0.004838 \\
7\end{array}$ & 1.33 & 0.012 & 1.02 & 0.883 & $\begin{array}{l}\text { Isoflavone } \\
\text { reductase family } \\
\text { protein }\end{array}$ \\
\hline T5AIP9 & 0.71 & $\begin{array}{r}0.005729 \\
1\end{array}$ & 1.25 & 0.042 & 0.89 & 0.096 & $\begin{array}{l}\text { Mannitol-1- } \\
\text { phosphate } \\
\text { dehydrogenase }\end{array}$ \\
\hline T5A918 & 0.78 & $\begin{array}{r}0.089542 \\
4\end{array}$ & 1.27 & 0.015 & 0.99 & 0.961 & $\begin{array}{l}\text { Protein disulfide- } \\
\text { isomerase tigA }\end{array}$ \\
\hline Cluster 3 & & & & & & & \\
\hline $\begin{array}{l}\text { Protein } \\
\text { ID }\end{array}$ & ST vs. PR & p-value & PR vs. MF & p-value & ST vs. MF & p-value & Annotation \\
\hline T5AFX3 & 1.62 & 0.006 & 0.79 & 0.013 & 1.28 & 0.050 & Nor-1 \\
\hline T5AL96 & 1.87 & 0.0008 & 0.61 & 0.016 & 1.14 & 0.364 & Catalase \\
\hline T5A5N4 & 1.65 & 0.0008 & 0.62 & 0.017 & 1.02 & 0.856 & Catalase \\
\hline
\end{tabular}




\begin{tabular}{|c|c|c|c|c|c|c|c|}
\hline T5AP38 & 1.52 & 0.002 & 0.74 & 0.0001 & 1.12 & 0.135 & $\begin{array}{l}\text { Glucose-methanol- } \\
\text { choline } \\
\text { oxidoreductase }\end{array}$ \\
\hline T5A9I4 & 1.93 & 0.004 & 0.59 & 0.003 & 1.13 & 0.356 & $\begin{array}{l}\text { Alcohol } \\
\text { dehydrogenase } \\
\text { superfamily, zinc- } \\
\text { type }\end{array}$ \\
\hline T4ZY06 & 1.27 & 0.003 & 0.67 & 0.007 & 0.86 & 0.156 & $\begin{array}{l}\text { Extradiol ring- } \\
\text { cleavage } \\
\text { dioxygenase }\end{array}$ \\
\hline T5A6F1 & 1.50 & 0.054 & 0.69 & 0.011 & 1.04 & 0.807 & $\begin{array}{l}\text { Superoxide } \\
\text { dismutase }\end{array}$ \\
\hline T5AA62 & 1.86 & 0.005 & 0.74 & 0.007 & 1.39 & 0.037 & $\begin{array}{l}\text { Alcohol } \\
\text { dehydrogenase } \\
\text { superfamily, zinc- } \\
\text { type }\end{array}$ \\
\hline T5A413 & 1.87 & 0.165 & 0.46 & 0.0001 & 0.87 & 0.614 & $\begin{array}{l}\text { L-threonine } \\
\text { dehydrogenase }\end{array}$ \\
\hline T5AF35 & 1.47 & 0.001 & 0.86 & 0.304 & 1.27 & 0.065 & Transaldolase \\
\hline T4ZWU2 & 1.27 & 0.003 & 0.68 & 0.007 & 0.861 & 0.156 & $\begin{array}{l}\text { Mitochondrial } \\
\text { peroxiredoxin } \\
\text { PRX1 }\end{array}$ \\
\hline
\end{tabular}

Cluster 4

\begin{tabular}{|c|c|c|c|c|c|c|c|}
\hline $\begin{array}{l}\text { Protein } \\
\text { ID }\end{array}$ & ST vs. PR & p-value & PR vs. MF & p-value & ST vs. MF & p-value & Annotation \\
\hline T5A9T9 & 2.10 & 0.042 & 1.79 & 0.048 & 3.77 & 0.015 & $\begin{array}{l}\text { AhpC/TSA family } \\
\text { protein }\end{array}$ \\
\hline T5AHW7 & 1.52 & 0.0009 & 1.21 & 0.002 & 1.84 & 0.0002 & $\begin{array}{l}\text { Flavin-containing } \\
\text { monooxygenase }\end{array}$ \\
\hline T5A9V1 & 1.04 & 0.659 & 1.34 & 0.011 & 1.39 & 0.021 & $\begin{array}{l}\text { Glutathione } \\
\text { peroxidase }\end{array}$ \\
\hline T5ACE9 & 1.86 & 0.0007 & 0.98 & 0.836 & 1.81416 & 0.001 & $\begin{array}{l}\text { WSC domain } \\
\text { containing protein }\end{array}$ \\
\hline T5AHU7 & 1.16 & 0.338 & 1.25 & 0.029 & 1.46 & 0.053 & $\begin{array}{l}\text { NADPH-- } \\
\text { cytochrome } \quad \mathrm{P} 450 \\
\text { reductase }\end{array}$ \\
\hline $\mathrm{T} 5 \mathrm{ABX} 3$ & 1.71 & 0.043 & 1.44 & 0.046 & 2.46672 & 0.011 & $\begin{array}{l}\text { NAD }(\mathrm{P}) \text {-binding } \\
\text { domain protein }\end{array}$ \\
\hline T5AJL9 & 1.08 & 0.279 & 1.34 & 0.0003 & 1.44362 & 0.002 & $\begin{array}{l}\text { 2-nitropropane } \\
\text { dioxygenase }\end{array}$ \\
\hline
\end{tabular}




\begin{tabular}{|c|c|c|c|c|c|c|c|}
\hline T5AAS5 & 1.85 & 0.002 & 0.95 & 0.718 & 1.75728 & 0.003 & Peroxiredoxin \\
\hline T4ZZN0 & 1.12 & 0.124 & 1.21 & 0.026 & 1.36058 & 0.023 & $\begin{array}{l}\text { Scavenger mRNA } \\
\text { decapping enzyme }\end{array}$ \\
\hline T5ADL3 & 1.82 & 0.038 & 1.27 & 0.037 & 2.31 & 0.017 & $\begin{array}{l}\text { C-1- } \\
\text { tetrahydrofolate } \\
\text { synthase }\end{array}$ \\
\hline
\end{tabular}

